\title{
Accurate description of low-lying excited states in a series of photoreactive clusters [Os3(CO) 10( $\alpha$-diimine)] by DFT calculations
}

Article

Accepted Version

Hartl, F., Bakker, M. J., Santos, V. F., Costa, P. J. and Calhorda, M. J. (2018) Accurate description of low-lying excited states in a series of photoreactive clusters [Os3(CO) $10(\alpha$-diimine)] by DFT calculations. Inorganic Chemistry, 57 (18). pp. 11704-11716. ISSN 0020-1669 doi: https://doi.org/10.1021/acs.inorgchem.8b01847 Available at https://centaur.reading.ac.uk/79078/

It is advisable to refer to the publisher's version if you intend to cite from the work. See Guidance on citing.

To link to this article DOI: http://dx.doi.org/10.1021/acs.inorgchem.8b01847

Publisher: American Chemical Society

All outputs in CentAUR are protected by Intellectual Property Rights law, including copyright law. Copyright and IPR is retained by the creators or other copyright holders. Terms and conditions for use of this material are defined in the End User Agreement. 


\section{www.reading.ac.uk/centaur}

\section{CentAUR}

Central Archive at the University of Reading

Reading's research outputs online 
This document is confidential and is proprietary to the American Chemical Society and its authors. Do not copy or disclose without written permission. If you have received this item in error, notify the sender and delete all copies.

\section{Accurate Description of Low-Lying Excited States in a Series of Photoreactive Clusters [Os3(CO)10(a-diimine)] by DFT Calculations}

\begin{tabular}{|r|l|}
\hline Journal: & Inorganic Chemistry \\
\hline Manuscript ID & ic-2018-01847e.R1 \\
\hline Manuscript Type: & Article \\
\hline Date Submitted by the Author: & $\mathrm{n} / \mathrm{a}$ \\
\hline Complete List of Authors: & $\begin{array}{l}\text { Hartl, Frantisek; University of Reading, Department of Chemistry } \\
\text { Bakker, Maarten; Oce Technologies BV } \\
\text { Farelo dos Santos, Vanessa; Universidade Federal do Rio de Janeiro, } \\
\text { Instituto de química } \\
\text { Costa, Paulo; Departamento de Química e Bioquímica, CQB, Faculdade de } \\
\text { Ciências Universidade de Lisboa } \\
\text { Calhorda, Maria; Faculty of Science, University of Lisboa, Department of } \\
\text { Chemistry and Biochemist }\end{array}$ \\
\hline
\end{tabular}




\title{
Accurate Description of Low-Lying Excited States in a Series of Photoreactive Clusters $\left[\mathrm{Os}_{3}(\mathrm{CO})_{10}(\alpha-\right.$ diimine $\left.)\right]$ by DFT Calculations
}

František Hartl, ${ }^{*, a, b}$ Maarten J. Bakker, ${ }^{\mathrm{a}, \mathrm{c}}$ Vanessa F. Santos, ${ }^{\mathrm{d}, \mathrm{e}}$ Paulo J. Costa, ${ }^{\mathrm{d}}$ Maria José Calhorda*,d

${ }^{a}$ Institute of Molecular Chemistry, University of Amsterdam, Nieuwe Achtergracht 166, 1018 WV Amsterdam, The Netherlands.

${ }^{\mathrm{b}}$ Current affiliation: Department of Chemistry, University of Reading, Whiteknights, Reading, RG6 6AD, UK

${ }^{\mathrm{c}}$ Current affiliation: Océ Technologies, P.O. Box 101, 5900 MA Venlo, The Netherlands

${ }^{\mathrm{d}}$ Centro de Química e Bioquímica and BioISI - Biosystems \& Integrative Sciences Institute, Departamento de Química e Bioquímica, Faculdade de Ciências, Universidade de Lisboa, 1749016 Lisboa, Portugal e Instituto de Química, Universidade Federal do Rio de Janeiro, 21941-909 Rio de Janeiro, RJ, Brazil

\begin{abstract}
Density functional theory (DFT) calculations were performed on the clusters $\left[\mathrm{Os}_{3}(\mathrm{CO})_{10}(\alpha-\right.$ diimine)], for $\alpha$-diimine $=2,2$ '-bipyridine (BPY), $N$-isopropyl 2-iminomethylpyridine (IMP), and $N, N^{\prime}$-diisopropyl-1,4-diaza-1,3-butadiene (DAB), together with their spectroscopic study. This important family of clusters is known to convert upon irradiation with visible light into short-lived biradicals and long-lived zwitterions from a $\sigma \pi^{*}$ (SBLCT) excited state that, however, has not been described accurately thus far by quantum mechanical calculations. Based on the combined DFT, UV-vis absorption and resonance Raman data, the lowest-lying visible absorption band is assigned to a $\sigma(\mathrm{Os} 1-\mathrm{Os} 3)$-to- $\pi^{*}(\alpha$-diimine $) \mathrm{CT}$ transition for $\alpha$-diimine $=$ bpy and IMP, and to a strongly delocalized $\sigma(\mathrm{Os} 1-\mathrm{Os} 3) \pi^{*}$-to- $\sigma^{*}(\mathrm{Os} 1-\mathrm{Os} 3) \pi^{*}$ transition for conjugated non-aromatic $\alpha-$ diimine $=\mathrm{DAB}$. The DFT calculations rationalize the experimentally determined characteristics of this electronic transition in the studied series: (i) the corresponding absorption band is the dominant feature in the visible spectral region, (ii) the CT character of the electronic excitation


declines from $\alpha$-diimine $=$ bpy to IMP and vanishes for DAB, (iii) the excitation energies decrease in the order $\alpha$-diimine $=\mathrm{DAB}>\mathrm{BPY}>\mathrm{IMP}$, (iv) the oscillator strength shrinks in the order $\alpha$ diimine $=\mathrm{DAB}>\mathrm{IMP}>\mathrm{BPY}$. Reference photoreaction quantum yields measured accurately for the formation of a cluster zwitterion from $\left[\mathrm{Os}_{3}(\mathrm{CO})_{10}(\mathrm{IMP})\right]$ in strongly coordinating pyridine, demonstrate that the optical population of the lowest-energy ${ }^{1} \sigma \pi^{*}$ and relaxed ${ }^{3} \sigma \pi^{*}$ excited states in the DFT model scheme is still capable of inducing the initial homolytic Os1-Os3 $\sigma$-bond splitting, although less efficiently than the optical excitation into neighbor higher-lying electronic transitions due to a higher potential barrier for the reaction from a dissociative $\left(\sigma \sigma^{*}\right)$ state.

\section{Keywords}

Osmium carbonyl, Cluster, $\alpha$-Diimine, TDDFT, Resonance Raman, Charge transfer, Biradical, Zwitterion

\section{Introduction}

Triangular clusters of the type $\left[\mathrm{Os}_{3}(\mathrm{CO})_{10}(\alpha\right.$-diimine $\left.)\right]$ possess a diverse and intriguing photochemistry that has been thoroughly studied over the last twenty years. ${ }^{1,2,3,4,5,6,7,8,9,10}$ On irradiation with visible light the clusters undergo Os-Os( $\alpha$-diimine) bond cleavage reactions. Controlled by the coordinating ability of the solvent, the nature of the $\alpha$-diimine ligand and temperature, zwitterionic and/or biradical photoproducts are formed, which either regenerate the parent cluster or rearrange to stable open-structure isomers with the reactive $\mathrm{C}=\mathrm{N}$ imino bond in $N$-isopropyl 2-iminomethylpyridine (iPr-IMP), and $N, N^{\prime}$-diisopropyl-1,4-diaza-1,3-butadiene (iPr$\mathrm{DAB}$ ) converted to form a bridge between the Os1 and Os3 centres (see Scheme 1). 


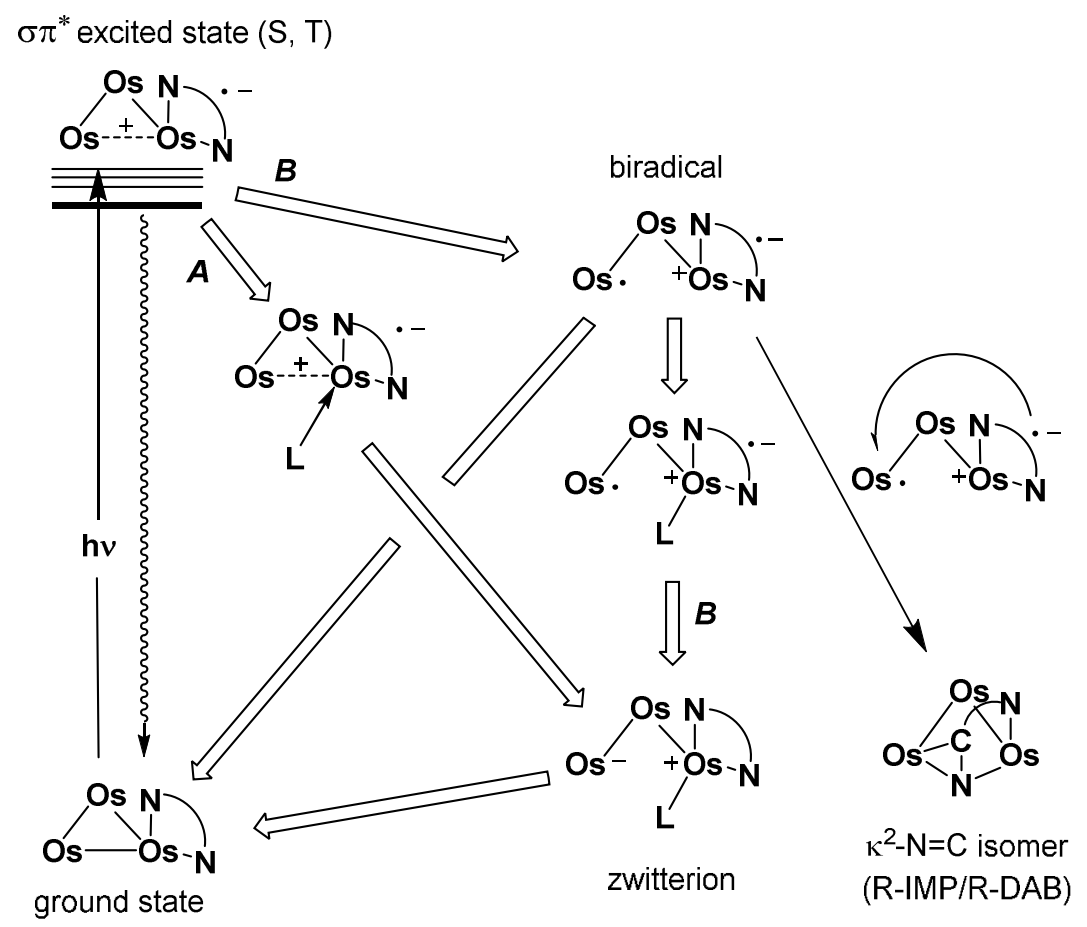

Scheme 1. Photoreactivity of $\left[\mathrm{Os}_{3}(\mathrm{CO})_{10}(\alpha\right.$-diimine $\left.)\right]$ from an optically populated $\sigma \pi^{*}$ excited state; $\mathrm{L}=$ Lewis base, e.g., donor solvent, olefin, pedant $N$-alkylamine side arm at $\alpha$-diimine. Diamagnetic zwitterions are formed either via the ultrafast (ps) exciplex path $A$ or the slower ( $\mu$ s) biradical path $B$.

In analogy with binuclear metal-metal bonded complexes such as $\left[(\mathrm{CO})_{5} \mathrm{Mn}-\mathrm{Mn}(\mathrm{CO})_{3}(\alpha-\right.$ diimine)], ${ }^{11,12,13,14}$ irradiation into the lowest-energy absorption band of the triosmium clusters in the visible spectral region was initially proposed to populate a $\mathrm{d}_{\pi}(\mathrm{Os})$-to- $\pi^{*}(\alpha$-diimine $)$ charge transfer (MLCT) excited state. This primary event was thought to be followed by intersystem crossing to a reactive $\sigma \pi^{*}$ state, $\sigma$ representing a cluster-core bonding orbital, in which an OsOs( $\alpha$-diimine $)$ bond is significantly weakened and finally split. The original description was later thoroughly revised, ${ }^{8,10}$ see below.

$\mathrm{DFT}^{15}$ and $\mathrm{TDDFT}^{16}$ calculations were performed in order to obtain a deeper insight into the electronic structure of $\left[\mathrm{Os}_{3}(\mathrm{CO})_{10}(\alpha\right.$-diimine $\left.)\right]$ clusters, where $\alpha$-diimine $=2,2^{\prime}$-bipyridine (BPY), $N$-isopropyl 2-iminomethylpyridine (iPr-IMP), and $N, N^{\prime}$-diisopropyl-1,4-diaza-1,3butadiene (iPr-DAB) (see Chart 1). Earlier calculations, using truncated $\alpha$-diimine models (H-IMP and H-DAB for iPr-IMP and Pr-DAB) and BPY, showed limitations in addressing the photoreactivity, and the resulting publication dealt only with their molecular and electronic structures. ${ }^{17}$ Indeed, a comparison with the single crystal structures of the iPr-DAB and BPY 
clusters, ${ }^{18,19}$ shows that the calculated Os-Os bond lengths were longer by an amount larger than normally accepted $(\sim 0.1 \AA$, see below). On the other hand, it was hardly possible to predict the trend of the wavelength of the lowest energy absorption maxima of the three clusters, viz. 558, 582, and $521 \mathrm{~nm}$ for $\alpha$-diimine $=$ BPY, iPr-IMP and iPr-DAB, respectively. These discrepancies limited our trust in the reliability of the interpretation of the experimental results. Considering the recent developments in computational methodologies, such as better functionals and basis sets, we decided to revisit this problem, and found more satisfying answers that will be compared to the previous ones. In this work, DFT and TDFT calculations are used in combination with electronic absorption and resonance Raman (rR) spectroscopy to assign the visible absorption bands, focusing on the lowest energy electronic transitions, and to evaluate the influence of the $\alpha$-diimine ligand. On the grounds of the DFT calculations and measurements of wavelength- and temperature-dependent photoreaction quantum yields of the zwitterion formation, plausible models of the latter photoreaction are discussed. This contribution is the last one in a comprehensive series, following the insightful time-resolved (ps- $\mu \mathrm{s})$ spectroscopic (TA, TR-IR) studies of the $\left[\mathrm{Os}_{3}(\mathrm{CO})_{10}(\mathrm{iPr}-\mathrm{IMP})\right]^{10}$ and $\left[\mathrm{Os}_{3}(\mathrm{CO})_{10}(\mathrm{iPr}-\mathrm{IEP})\right]^{8}$ clusters (Chart 1) published with correct mechanistic conclusions but lacking a reliable theoretical support for the explicit assignment and detailed description of the optically populated excited states.

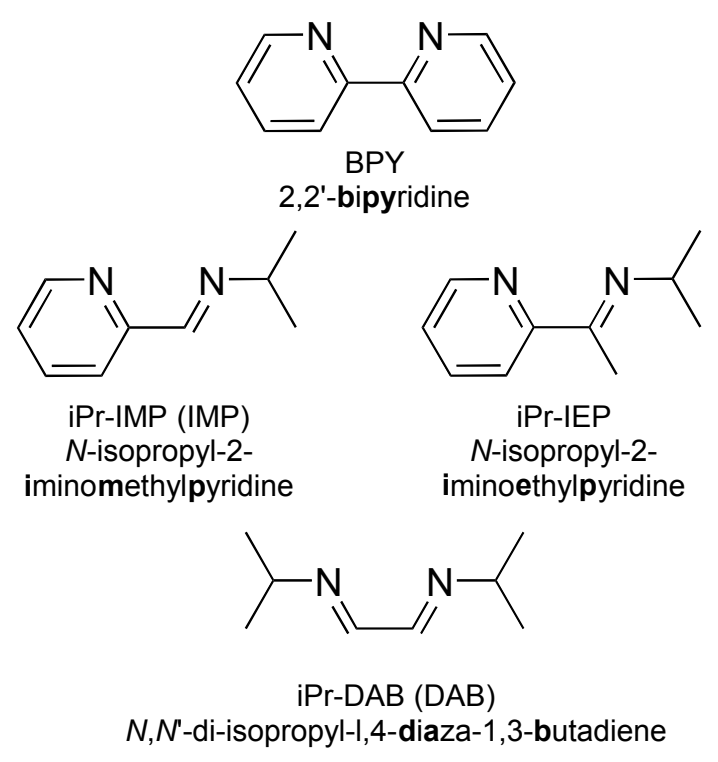

Chart 1. Schematic representation of the $\alpha$-diimine ligands. Note that in the $\left[\mathrm{Os}_{3}(\mathrm{CO})_{10}(\alpha-\right.$ diimine)] literature ${ }^{8,10}$, iPr-IMP is denoted as iPr-PyCa, and iPr-IEP as iPr-AcPy. 


\section{Results and Discussion}

\section{Molecular and electronic structure}

The geometries of the three studied clusters were obtained by having optimized the accessible experimental structures of $\left[\mathrm{Os}_{3}(\mathrm{CO})_{10}(\mathrm{BPY})\right]^{19}$ and $\left[\mathrm{Os}_{3}(\mathrm{CO})_{10}(\mathrm{PPr}-\mathrm{DAB})\right]^{18}$. There are three isomers of $\left[\mathrm{Os}_{3}(\mathrm{CO})_{10}(\mathrm{iPr}-\mathrm{IMP})\right]$ and the model considered in this work corresponds to the most stable one ${ }^{17}$ (N.B. iPr-IMP will further be abbreviated in the text, and in Abstract, as IMP, and iPr$\mathrm{DAB}$ as $\mathrm{DAB}$ ). The geometries and relative energies are given in Figure S1 (Supporting Information). Since the computational approach used earlier ${ }^{17}$ had severe limitations, we tested several functionals and basis sets to find the best methodology and describe both the geometry and the electronic absorption spectra of the three clusters. As a result, we have chosen the CAMB3LYP functional, with a LANL2TZ(f) basis set for osmium and 6-311++ $\mathrm{G}^{* *}$ for the remaining atoms (see Computational Details). The optimized geometries of gas-phase ground state with indication of some selected distances are displayed in Figure 1 (top line), along with the two single-crystal X-ray structures of the $\mathrm{BPY}^{19}$ and $\mathrm{DAB}^{18}$ clusters (available from the CSD database $^{20}$ ) and the numbering scheme.

The agreement between the two experimental structures and the corresponding calculated ground-state gas-phase structures is very reasonable, with deviations of the Os-Os bond lengths below $0.04 \AA$, and far better than the values obtained in the previous study. ${ }^{17}$ The geometry optimization was also carried out for the three clusters, taking into account the effect of the solvent (toluene); however, the bond lengths in general increased only slightly and the agreement with the experimental values became worse (Table 1).

We have also optimized the first triplet and singlet excited states (see Computational Details). The changes in geometry are not large; therefore, the optimized structures are very similar to those presented in Figure 1. The relevant distances are collected in Table 1. The changes in bond lengths are almost the same, in the lowest-energy singlet and lowest energy triplet excitedstate structures. Additionally, the patterns for the DAB cluster are also different from the two other clusters. In the ground state, the three Os-Os bonds are approximately of the same length (within $<0.1 \AA$ ), the shortest Os-Os bond being Os1-Os2 (BPY, IMP) or Os2-Os3 (DAB). In the first singlet excited state, these three bonds are elongated in the DAB cluster, while two are elongated in the IMP and BPY clusters (Os1-Os2 and Os1-Os3) and the third, Os2-Os3, shortens. In the first triplet excited state, the Os1-Os3 bond (highlighted in bold in Table 1) becomes the longest in all three clusters, varying from 2.962 to $2.972 \AA$ in the IMP cluster, from 2.900 to $3.035 \AA$ in the DAB one, and from 2.941 to $3.012 \AA$ in the BPY cluster. However, Os1- 
Os 2 changes more significantly (from 2.882 to $2.959 \AA$ ) in IMP. It is therefore likely that one of the Os-Os bonds adjacent to the $\alpha$-diimine ligand will cleave after light absorption, both in the singlet and triplet excited state.

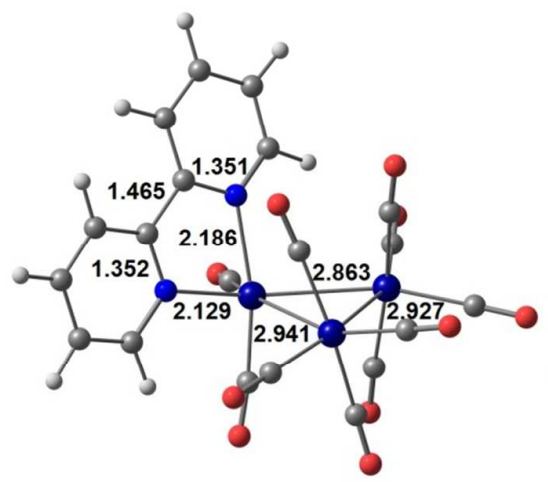

BPY

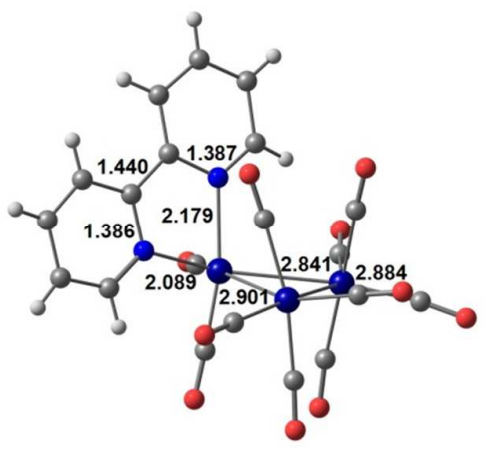

RIKCIX

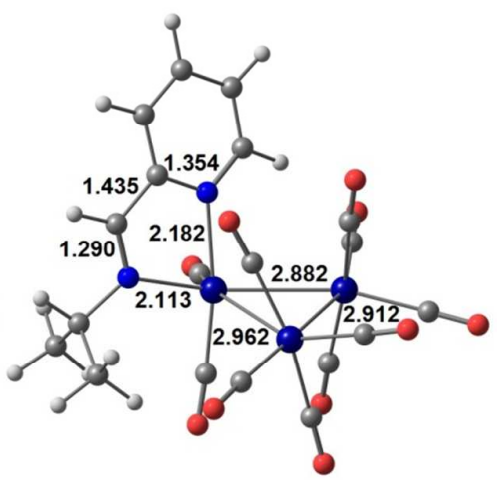

IMP

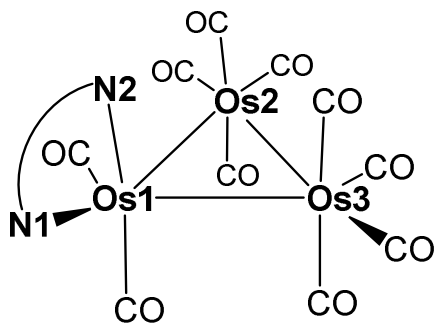

Figure 1 DFT-optimized geometries of $\left[\mathrm{Os}_{3}(\mathrm{CO})_{10}(\alpha\right.$-diimine $\left.)\right](\alpha$-diimine $=$ BPY, IMP, DAB $)$ in the gas-phase ground state (top), the single crystal X-ray structures, along with their respective CSD refcodes, ${ }^{20}$ of the $\mathrm{BPY}^{19}$ (bottom, left) and $\mathrm{DAB}^{18}$ (bottom right) clusters, and the numbering scheme (bottom, centre).

The distances within the chelate ring differ between the DAB and the BPY or IMP clusters, reflecting a different participation of the $\mathrm{DAB} \pi$ orbitals in the occupied orbitals (see below). In $\mathrm{DAB}$, the $\mathrm{C}-\mathrm{C}$ and $\mathrm{C}-\mathrm{N}$ distances are similar (1.322, 1.326, and $1.388 \AA$, respectively), while for both BPY and IMP the short C-N bonds (1.351, $1.352 \AA$ for BPY and 1.354, $1.290 \AA$ for IMP) alternate with a long $\mathrm{C}-\mathrm{C}$ bond (1.465 $\AA$ for BPY and $1.435 \AA$ for IMP). In the excited states, the $\mathrm{C}-\mathrm{C}$ and $\mathrm{C}-\mathrm{N}$ bonds of the DAB cluster keep the same trend $(\mathrm{C}-\mathrm{N} 1.323,1.334 \AA$ and $\mathrm{C}-\mathrm{C} 1.397$ $\AA$ in the triplet, for instance) since both the LUMO and HOMO are delocalized over the osmium 
atoms and DAB (see next section). On the other hand, both in BPY and IMP, the HOMO is localized on the metals and the LUMO on the $\alpha$-diimine ligand. Photoexcitation of one electron leads to the population of the LUMO ( $\mathrm{C}-\mathrm{C}$ bonding and $\mathrm{C}-\mathrm{N}$ antibonding, see the next section), causing some shrinking of the central C-C bond (ca. 0.04-0.05 $\AA$ ) and expansion of the $\mathrm{C}-\mathrm{N}$ bonds (ca.0.02-0.03 $\AA$ ). The clusters have no symmetry, but the distances of equivalent ligand bonds differ more in IMP (asymmetric ligand) than in BPY.

Table 1. Experimental (RIKCIX and GIRDEQ) and DFT/CAM-B3LYP calculated relevant bond distances $(\AA)$ in the three clusters $\left[\mathrm{Os}_{3}(\mathrm{CO})_{10}(\alpha\right.$-diimine $\left.)\right](\alpha$-diimine $=$ BPY, IMP, DAB $)$ in the ground state (GS), both in the gas phase and in toluene, and in the gas-phase singlet (S) and triplet (T) $\sigma \pi^{*}$ (BPY, IMP; Scheme 1) or mixed $\sigma \sigma^{*} / \pi \pi^{*}$ (DAB) excited states (for details, see the following section).

\begin{tabular}{|c|c|c|c|c|c|}
\hline Bond & Experimental & GS (gas phase) & GS (toluene) & Excited state (T) & Excited state (S) \\
\hline \multicolumn{6}{|c|}{$\left[\mathrm{Os}_{3}(\mathrm{CO})_{10}(\mathrm{BPY})\right]$} \\
\hline Os1-Os2 & 2.841 & 2.863 & 2.889 & 2.934 & 2.868 \\
\hline Os1-Os3 & 2.901 & 2.941 & 2.972 & 3.012 & 3.137 \\
\hline Os2-Os3 & 2.884 & 2.927 & 2.940 & 2.884 & 2.871 \\
\hline Os1-N1 & 2.089 & 2.129 & 2.131 & 2.103 & 2.099 \\
\hline Os1-N2 & 2.179 & 2.196 & 2.189 & 2.150 & 2.157 \\
\hline \multicolumn{6}{|c|}{$\left[\mathrm{Os}_{3}(\mathrm{CO})_{10}(\mathrm{IMP})\right]$} \\
\hline Os1-Os2 & - & 2.882 & 2.896 & 2.959 & 2.906 \\
\hline Os1-Os3 & - & 2.962 & 2.962 & 2.972 & 3.165 \\
\hline Os2-Os3 & - & 2.912 & 2.920 & 2.880 & 2.870 \\
\hline Os1-N1 & - & 2.182 & 2.195 & 2.184 & 2.158 \\
\hline Os1-N2 & - & 2.113 & 2.122 & 2.110 & 2.100 \\
\hline \multicolumn{6}{|c|}{$\left[\mathrm{Os}_{3}(\mathrm{CO})_{10}(\mathrm{DAB})\right]$} \\
\hline Os1-Os2 & 2.876 & 2.907 & 2.920 & 2.929 & 2.951 \\
\hline Os1-Os3 & 2.880 & 2.900 & 2.926 & 3.035 & 3.349 \\
\hline Os2-Os3 & 2.867 & 2.884 & 2.921 & 2.887 & 2.957 \\
\hline Os1-N1 & 2.066 & 2.040 & 2.044 & 2.103 & 2.103 \\
\hline Os1-N2 & 2.115 & 2.087 & 2.092 & 2.171 & 2.109 \\
\hline
\end{tabular}




\section{Electronic Absorption Spectra and Excitation Energies}

The near-UV-vis absorption spectra of the clusters $\left[\mathrm{Os}_{3}(\mathrm{CO})_{10}(\alpha\right.$-diimine $\left.)\right](\alpha$-diimine $=\mathrm{BPY}$, IMP, DAB) in toluene are presented in Figure 2 and summarized in Table 2. In the visible region, the spectra are characterized by a dominant lowest-energy band with the absorption maximum between 520 and $600 \mathrm{~nm}$. For $\alpha$-diimine $=$ BPY and IMP the visible absorptions are strongly solvatochromic. To analyze the solvatochromic behavior, the transition energies were plotted versus the empirical solvent parameter $\mathrm{E}^{*}{ }_{\mathrm{MLCT}}$ of Manuta and Lees, ${ }^{21}$ which is based on the solvatochromism of the lowest MLCT transition of [W(CO) $\left.)_{4}(\mathrm{BPY})\right]$. For the lowest-energy absorption band of the three clusters, the solvent dependence is shown in Figure 3. Linear regression could well fit all the plots. Their slope reflects the degree of solvatochromism, whereas the intercept at $\mathrm{E}^{*}{ }_{\mathrm{MLCT}}=0$ corresponds to the experimental transition energy extrapolated to apolar isooctane, a solvent that will similarly interact with ground and excited states. Therefore, the extrapolated values for the experimental transition energy, $E_{\exp }$, are best compared with the calculated energies that refer to isolated 'gas-phase' molecules at $0 \mathrm{~K}$ (see Tables 2 and 3).

In the UV-vis spectrum of $\left[\mathrm{Os}_{3}(\mathrm{CO})_{10}(\mathrm{IMP})\right]$ two shoulders can be distinguished at the highenergy side (ca. 470 and $530 \mathrm{~nm}$ ) of the absorption band at $602 \mathrm{~nm}$ (see Figure 2). These absorptions are also strongly solvatochromic. By contrast, the two shoulders at the low-energy side (ca. 395 and $360 \mathrm{~nm}$ ) of an intense absorption in the near-UV region are not sensitive to solvent variation. For $\left[\mathrm{Os}_{3}(\mathrm{CO})_{10}(\mathrm{BPY})\right]$ the solvatochromism of the intense lowest-lying absorption band at $588 \mathrm{~nm}$ and the only resolved shoulder at its high-energy side (ca. $495 \mathrm{~nm}$ ) is even stronger than encountered for the IMP derivative. Again, the near-UV set of shoulders at ca. 400 and $360 \mathrm{~nm}$ are not solvatochromic. In contrast to the latter two clusters, none of the near$\mathrm{UV}$-vis absorptions of $\left[\mathrm{Os}_{3}(\mathrm{CO})_{10}(\mathrm{DAB})\right]$ is solvent-dependent, pointing to a negligible change in the molecular dipole moment upon the photoexcitation typically accompanying charge-transfer transitions. Notably, the lowest-energy absorption band of $\left[\mathrm{Os}_{3}(\mathrm{CO})_{10}(\mathrm{DAB})\right]$ at $521 \mathrm{~nm}$ is markedly blue-shifted compared to the clusters with the more basic BPY and IMP ligands. The two absorption features at 400 and $360 \mathrm{~nm}$ are common in the cluster series. 


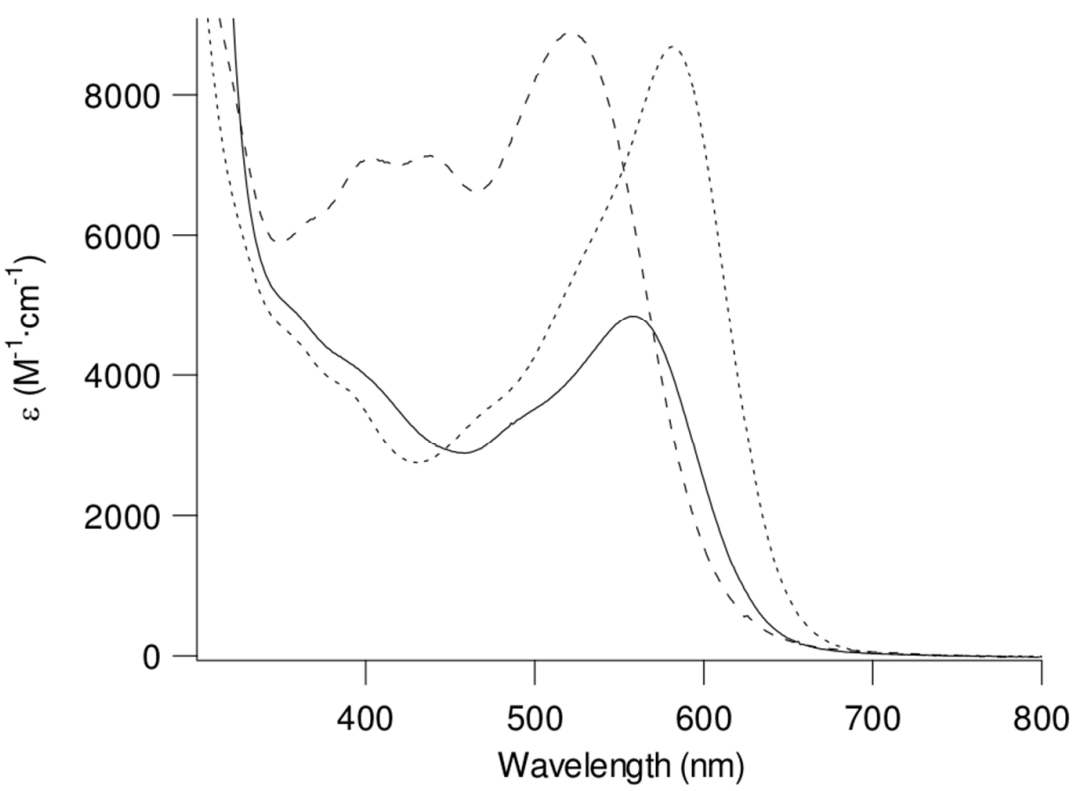

Figure 2. Experimental electronic absorption spectra of $\left[\mathrm{Os}_{3}(\mathrm{CO})_{10}(\alpha\right.$-diimine $\left.)\right]$ for $\alpha$-diimine $=$ bpy $(-), \operatorname{IMP}(\cdots)$ and DAB (- - ) in toluene at $293 \mathrm{~K}$.

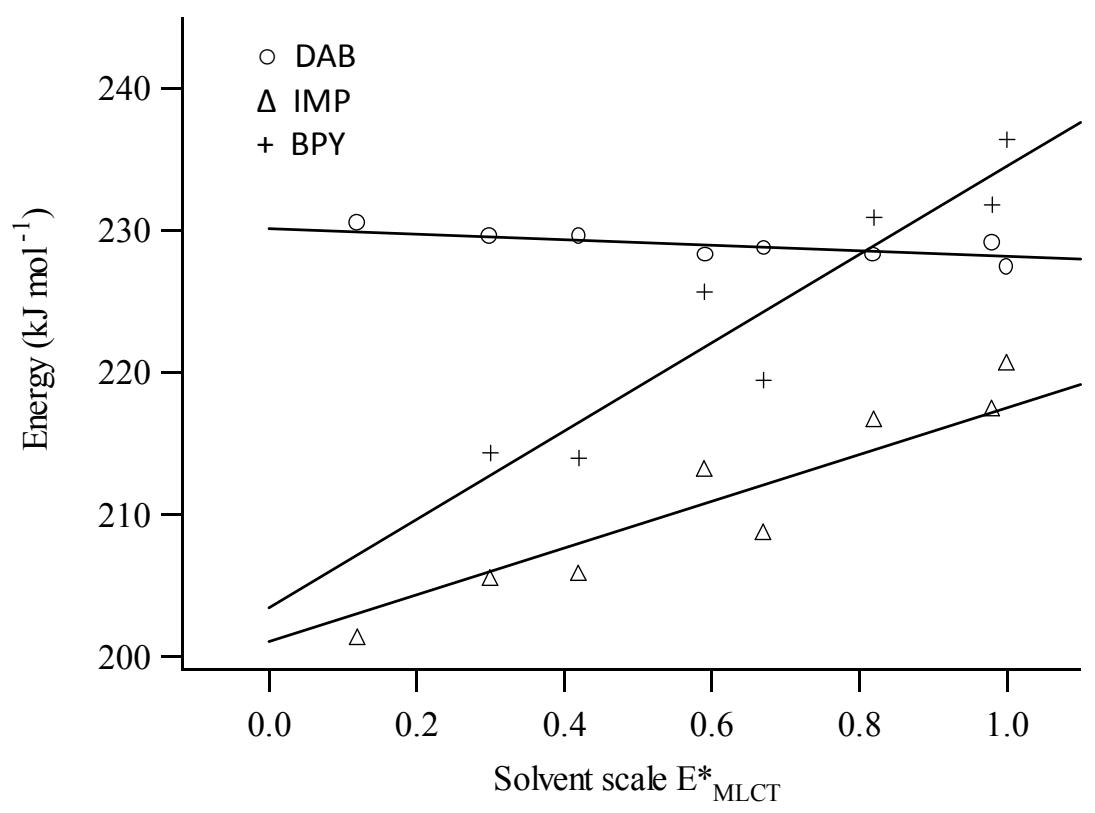

Figure 3. Solvatochromic behavior of the lowest-energy absorption band of $\left[\mathrm{Os}_{3}(\mathrm{CO})_{10}(\alpha-\right.$ diimine)] on the empirical solvent scale $\mathrm{E}^{*}{ }_{\mathrm{MLCT}}$ according to Manuta and Lees. ${ }^{21}$ The solvents used (with $\mathrm{E}^{*}{ }_{\text {MLCT }}$ in parentheses) were $\mathrm{CCl}_{4}\left(0.12\right.$; not measured for $\left[\mathrm{Os}_{3}(\mathrm{CO})_{10}(\mathrm{BPY})\right]$ due to its poor solubility), toluene (0.30), $\mathrm{CHCl}_{3}$ (0.42), THF (0.59), $\mathrm{CH}_{2} \mathrm{Cl}_{2}$ (0.67), acetone (0.82), acetonitrile (0.98) and DMSO (1.0). 


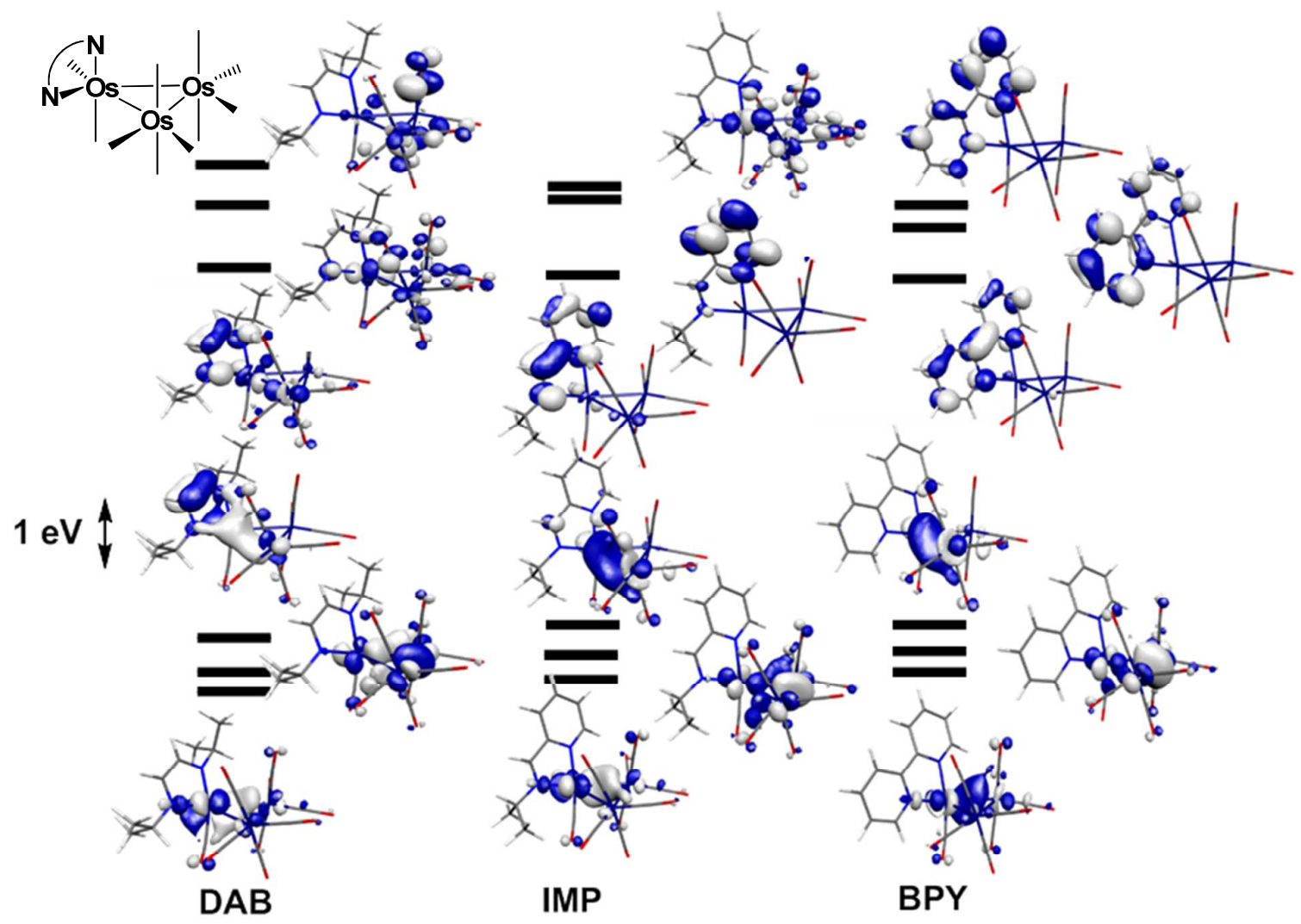

Figure 4. Frontier orbitals (HOMO-2, HOMO-1, HOMO, LUMO, LUMO+1 and LUMO+2) and relative energies (in $\mathrm{eV}$ ) of the three $\left[\mathrm{Os}_{3}(\mathrm{CO})_{10}(\alpha\right.$-diimine $\left.)\right]$ clusters $(\alpha$-diimine $=\mathrm{DAB}$, IMP, BPY).

TDDFT calculations ${ }^{16}$ were performed to obtain the electronic absorption spectra of the three clusters. In the previous study, ${ }^{17}$ the experimental energy order of the lowest energy band absorption of the three clusters (Figure 2) could not be reproduced. To solve this problem, we checked a variety of functionals (PBE1PBE, PW91PW91, B3LYP, CAM-B3LYP, M062X, see Computational details) and considered the isopropyl substituents on IMP and DAB. The electronic absorption spectra were calculated in the gas phase for all the functionals, and in toluene with CAM-B3LYP and M062X, on geometries also optimized in toluene. CAM-B3LYP was the only functional able to reproduce the observed trend in the gas phase (see Computational Details and Table S2 in Supporting Information). It should be added that the nature of the frontier orbitals and transitions is qualitatively the same in all the cases tested. The following results were obtained with the CAM-B3LYP functional in gas phase. 
The frontier orbitals differ significantly in the three $\alpha$-diimine clusters, as can be seen in Figure 4, where their relative energy and the 3D representations are depicted (see also the energy values in Table S1).

Table 2. Maxima and shoulders in the visible and near-UV absorption spectra of the clusters $\left[\mathrm{Os}_{3}(\mathrm{CO})_{10}(\alpha\right.$-diimine $\left.)\right]$.

\begin{tabular}{lllll}
\hline & $\lambda(\mathrm{nm})^{a}$ & $\varepsilon_{\max }\left(\mathrm{M}^{-1} \mathrm{~cm}^{-1}\right)^{a}$ & $\lambda(\mathrm{nm})^{b}$ & $E_{\text {exp }}(\mathrm{eV})^{b}$ \\
\hline Os/BPY & 558 & 4840 & 588 & 2.11 \\
& $492(\mathrm{sh})$ & $501(\mathrm{sh})$ & 2.47 \\
& $403(\mathrm{sh})$ & $405(\mathrm{sh})$ & 3.06 \\
& $357(\mathrm{sh})$ & $357(\mathrm{sh})$ & 3.47 \\
Os/IMP & 582 & 8700 & 602 & 2.06 \\
& $534(\mathrm{sh})$ & $548(\mathrm{sh})$ & 2.26 \\
& $467(\mathrm{sh})$ & $486(\mathrm{sh})$ & 2.55 \\
& $394(\mathrm{sh})$ & $394(\mathrm{sh})$ & 3.15 \\
& $358(\mathrm{sh})$ & $359(\mathrm{sh})$ & 3.45 \\
Os/DAB & 521 & 8900 & 519 & 2.39 \\
& 438 & & 437 & 2.84 \\
& 403 & 405 & 3.06 \\
& $367(\mathrm{sh})$ & $364(\mathrm{sh})$ & 3.41 \\
\hline
\end{tabular}

${ }^{a}$ In toluene. ${ }^{b}$ Extrapolated to $\mathrm{E}^{*} \mathrm{MLCT}=0$ (in isooctane) according to Manuta $e t a l^{21}$

The HOMO-LUMO gap in the series is not very different, ranging from $5.29 \mathrm{eV}$ in the DAB cluster to 4.90 and $4.91 \mathrm{eV}$ in the IMP and BPY, respectively. The HOMO, HOMO-1 and HOMO-2 are Os-Os $\sigma$-bonding orbitals, the three electron pairs contributing to the three bonds; however, they differ in the contribution of the $\alpha$-diimine ligand. There is no contribution in the case of BPY, and the contribution of IMP is residual, but $\pi_{2}$ of DAB is significantly involved, participating in a ligand-to-metal (Os1) donation. On the other hand, these three orbitals are also Os- $\mathrm{C}(\mathrm{O})$ slightly bonding or non-bonding, although the participation of the carbonyl groups is very small (Figure 4), especially for the BPY cluster. The three lowest unoccupied orbitals also differ. LUMO, LUMO+1 and LUMO+2 of $\left[\mathrm{Os}_{3}(\mathrm{CO})_{10}(\mathrm{BPY})\right]$ are pure $\pi^{*}(\mathrm{BPY})$ orbitals, with the carbonyls participating only in the LUMO+3 (not shown). In the IMP cluster, LUMO and LUMO +1 are non-bonding ligand $\pi^{*}$ orbitals, but LUMO+2 shows a strong contribution from $\mathrm{CO}$ 
$\pi^{*}$ and Os d orbitals. Finally, one DAB $\pi^{*}$ and CO $\pi^{*}$ orbitals contribute significantly to the LUMO, while both LUMO+1 and LUMO +2 are exclusively CO $\pi^{*}$. These trends are associated with the number and extension of the $\pi^{*}$ orbitals of each $\alpha$-diimine and the nature of these orbitals will determine the absorption features. The HOMO-LUMO gap is not determined by the energy of the $\alpha$-diimine $\pi^{*}$ orbitals, because some of them remain largely non-bonding (bpy), but others (DAB) participate strongly. The calculated (TDDFT) more intense low-energy transitions are listed in Table 3, with their composition and oscillator strength.

Table 3. Calculated and experimental excitation energies (eV) and oscillator strengths (OS)

\begin{tabular}{|c|c|c|c|c|c|c|}
\hline No. & $\lambda / \mathrm{nm}$ & $E / \mathrm{eV}$ & Composition (\%) & $E_{\text {exp }} / \mathrm{eV}^{a}$ & OS & $\mathrm{OS}_{\exp }^{b}$ \\
\hline \multicolumn{7}{|c|}{$\left[\mathrm{Os}_{3}(\mathrm{CO})_{10}(\mathrm{BPY})\right]$} \\
\hline 1 & 475 & 2.61 & $\mathrm{H} \rightarrow \mathrm{L}(94)$ & $2.11^{c}$ & 0.155 & 0.054 \\
\hline 2 & 408 & 3.04 & $\mathrm{H}-2 \rightarrow \mathrm{L}(17), \mathrm{H}-1 \rightarrow \mathrm{L}(66), \mathrm{H}-3 \rightarrow \mathrm{L}(8)$ & $2.47^{c}$ & 0.027 & \\
\hline 3 & 385 & 3.22 & $\mathrm{H}-2 \rightarrow \mathrm{L}(75), \mathrm{H}-1 \rightarrow \mathrm{L}(17)$ & & 0.013 & \\
\hline 4 & 376 & 3.30 & $\mathrm{H} \rightarrow \mathrm{L}+1(18), \mathrm{H} \rightarrow \mathrm{L}+3(67), \mathrm{H}-1 \rightarrow \mathrm{L}(3)$ & 3.06 & 0.013 & \\
\hline 5 & 348 & 3.56 & $\begin{array}{l}\mathrm{H}-4 \rightarrow \mathrm{L}(28), \mathrm{H}-1 \rightarrow \mathrm{L}+3(29), \mathrm{H}-3 \rightarrow \mathrm{L}(8), \\
\mathrm{H}-2 \rightarrow \mathrm{L}+3(5)\end{array}$ & & 0.017 & \\
\hline 6 & 328 & 3.78 & $\mathrm{H} \rightarrow \mathrm{L}+2(81), \mathrm{H} \rightarrow \mathrm{L}+1(5)$ & & 0.018 & \\
\hline 7 & 324 & 3.83 & $\begin{array}{l}\mathrm{H}-2 \rightarrow \mathrm{L}+3(49), \mathrm{H}-4 \rightarrow \mathrm{L}+3(8) \\
\mathrm{H}-3 \rightarrow \mathrm{L}(6), \mathrm{H}-2 \rightarrow \mathrm{L}+1(5), \mathrm{H}-1 \rightarrow \mathrm{L}+3(8)\end{array}$ & & 0.033 & \\
\hline
\end{tabular}

\begin{tabular}{ccclccc}
\hline \multicolumn{7}{c}{$\left[\mathrm{Os}_{3}(\mathrm{CO})_{10}(\mathrm{IMP})\right]$} \\
\hline 1 & 492 & 2.52 & $\mathrm{H} \rightarrow \mathrm{L}(93), \mathrm{H}-1 \rightarrow \mathrm{L}(3)$ & $2.06,2.26^{c}$ & 0.190 & \\
2 & 438 & 2.83 & $\mathrm{H}-1 \rightarrow \mathrm{L}(84), \mathrm{H}-3 \rightarrow \mathrm{L}(5), \mathrm{H} \rightarrow \mathrm{L}(3)$ & $2.55^{c}$ & 0.017 & \\
3 & 397 & 3.13 & $\mathrm{H}-2 \rightarrow \mathrm{L}(83), \mathrm{H}-3 \rightarrow \mathrm{L}(6), \mathrm{H}-1 \rightarrow \mathrm{L}(4)$ & 3.15 & 0.030 & \\
4 & 344 & 3.61 & $\mathrm{H}-1 \rightarrow \mathrm{L}+2(68), \mathrm{H}-4 \rightarrow \mathrm{L}(4), \mathrm{H}-2 \rightarrow \mathrm{L}+2(7)$ & 3.45 & 0.042 & \\
\hline & & & {$\left[\mathrm{Os}_{3}(\mathrm{CO})_{10}(\mathrm{DAB})\right]$} & & & \\
\hline 1 & 452 & 2.74 & $\mathrm{H} \rightarrow \mathrm{L}(89), \mathrm{H}-1 \rightarrow \mathrm{L}(5)$ & 2.39 & 0.168 & 0.132 \\
2 & 369 & 3.36 & $\mathrm{H}-3 \rightarrow \mathrm{L}(25), \mathrm{H} \rightarrow \mathrm{L}+1(56), \mathrm{H}-2 \rightarrow \mathrm{L}(4)$ & 2.84 & 0.085 & \\
3 & 366 & 3.39 & $\mathrm{H}-3 \rightarrow \mathrm{L}(35), \mathrm{H}-2 \rightarrow \mathrm{L}(13), \mathrm{H} \rightarrow \mathrm{L}+1(34)$ & 3.06 & 0.030 & \\
4 & 301 & 4.12 & $\mathrm{H}-6 \rightarrow \mathrm{L}(16), \mathrm{H}-4 \rightarrow \mathrm{L}(14), \mathrm{H}-3 \rightarrow \mathrm{L}+1$ & & &
\end{tabular}

$\mathrm{H}-1 \rightarrow \mathrm{L}+2(8)$ 
$52984.16 \quad \mathrm{H}-1 \rightarrow \mathrm{L}+2(57), \mathrm{H} \rightarrow \mathrm{L}+2(14)$ 0.020

\footnotetext{
${ }^{a}$ Experimental excitation energies, obtained by extrapolation (see Table 2). ${ }^{21 b}$ Experimental oscillator strengths calculated according to $f=4.319 .10^{-9} \times \varepsilon \times \Delta v$, with the molar absorption coefficient $\varepsilon$ and $\Delta v$ (the width of the absorption band at half height) in toluene. ${ }^{c}$ Corresponding absorptions show significant negative solvatochromism.
}

The calculated lowest-energy transition is shifted towards higher energies for all clusters, but the maxima follow the order $452 \mathrm{~nm}(\mathrm{DAB})<475 \mathrm{~nm}(\mathrm{BPY})<492 \mathrm{~nm}$ (IMP) as observed experimentally $(521<558<582 \mathrm{~nm}$, respectively). This transition is assigned as a $\sigma(\mathrm{Os} 1-\mathrm{Os} 3)$ to- $\pi^{*}(\alpha$-diimine $)$ for $\left[\mathrm{Os}_{3}(\mathrm{CO})_{10}(\mathrm{BPY})\right]$. It results from a pure $\mathrm{HOMO} \rightarrow \mathrm{LUMO}$ excitation (Table 3 ) and, considering the nature of the HOMO and LUMO (Figure 4) and the electron density difference maps, EDDM (Figure 5), it is an SBLCT band. Examples of CT transitions are Metalto-Ligand (MLCT or $\mathrm{d}_{\pi} \rightarrow \pi^{*}$ ), ${ }^{22,23,24}$ Halide (X)-to-Ligand (XLCT) ${ }^{25,26}$ or Sigma Bond-to-Ligand $\left(\mathrm{SBLCT} \text { or } \sigma \pi^{*}\right)^{14}$ excited states.

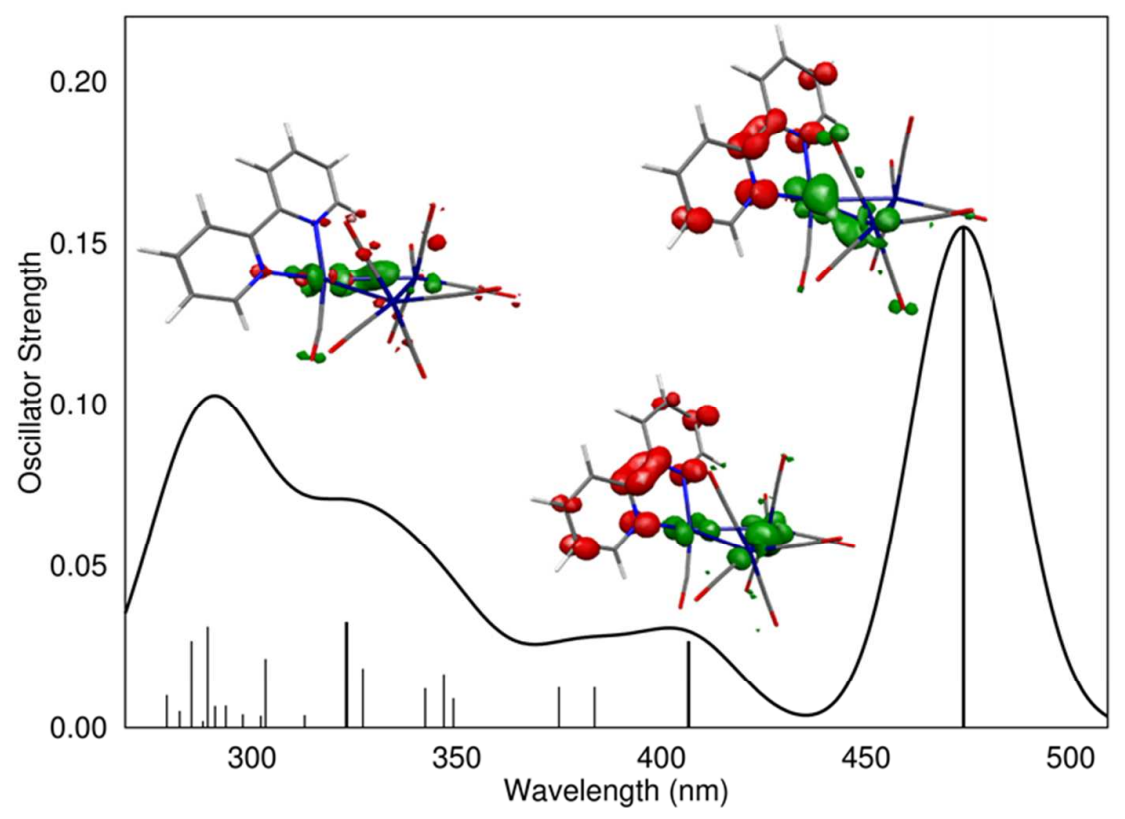

Figure 5. TD-DFT calculated excitations (vertical lines) and simulated electronic spectrum of $\left[\mathrm{Os}_{3}(\mathrm{CO})_{10}(\mathrm{BPY})\right]$. The EDDM plots for the relevant excitations (highlighted vertical lines) are also shown, green and red corresponding to a decrease and increase in electron density, respectively. 


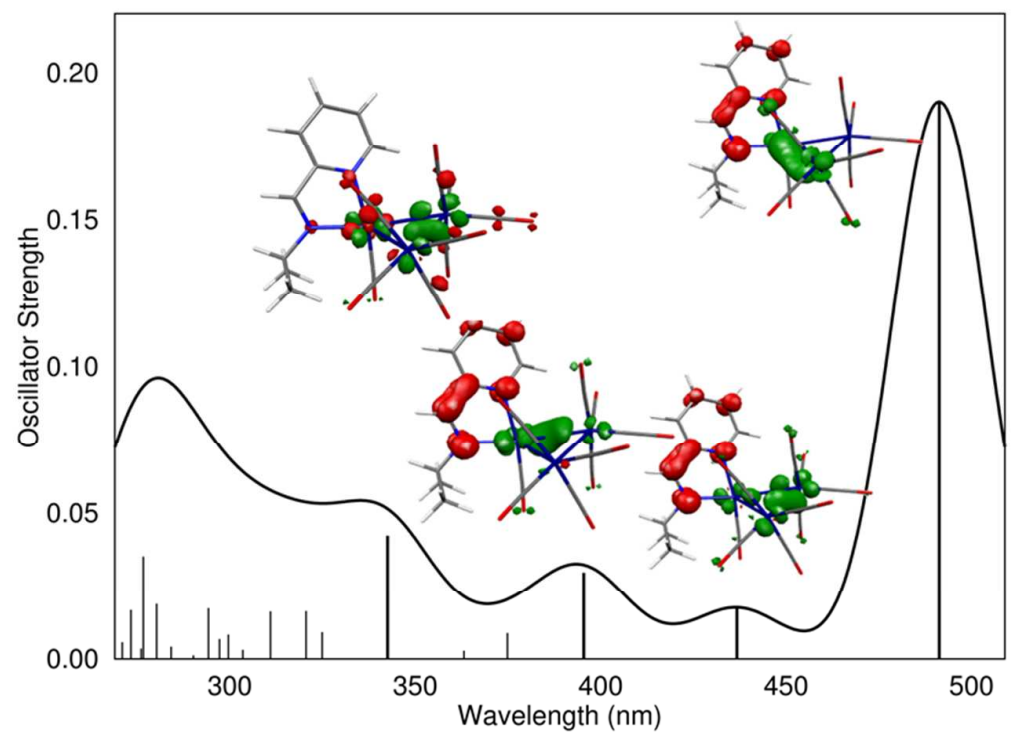

Figure 6. TD-DFT calculated excitations (vertical lines) and simulated electronic spectrum of $\left[\mathrm{Os}_{3}(\mathrm{CO})_{10}(\mathrm{IMP})\right]$. The EDDM plots for the relevant excitations (highlighted vertical lines) are also shown, green and red corresponding to a decrease and increase in electron density, respectively.

In the IMP cluster (Table 3, Figure 6), the lowest-energy transition results essentially from a HOMO $\rightarrow$ LUMO excitation (93\%), with a small contribution of HOMO-1 $\rightarrow$ LUMO. The $\sigma\left(\right.$ Os1-Os3)-to- $\pi^{*}(\alpha$-diimine) character is not as pronounced as for the BPY cluster, since the HOMO is slightly localized on the $\alpha$-diimine, and the LUMO is slightly Os1-IMP $\pi$-antibonding. In summary, this transition can still be assigned as $\operatorname{SBLCT}\left(\sigma \pi^{*}\right)$, in line with its solvatochromism, which is less marked than determined for BPY (see Figure 3).

Finally, for $\left[\mathrm{Os}_{3}(\mathrm{CO})_{10}(\mathrm{DAB})\right]$, the HOMO and LUMO are strongly delocalized (Table 3, Figure 4), both having contributions from osmium atoms (Os1-Os3 $\sigma$ and $\sigma^{*}$, respectively), DAB $\pi_{3} *$ and Os 3 carbonyls, while the HOMO- 1 is essentially Os1-Os2 $\sigma$. The lowest-energy transition will therefore have a strongly mixed character, namely $\sigma$-to- $\sigma^{*}($ Os1-Os3) and $\pi$-to- $\pi *(O s 2-$ DAB), with a negligible SBLCT (or MLCT) character and nearly zero dipole moment change (see Figure 7). 


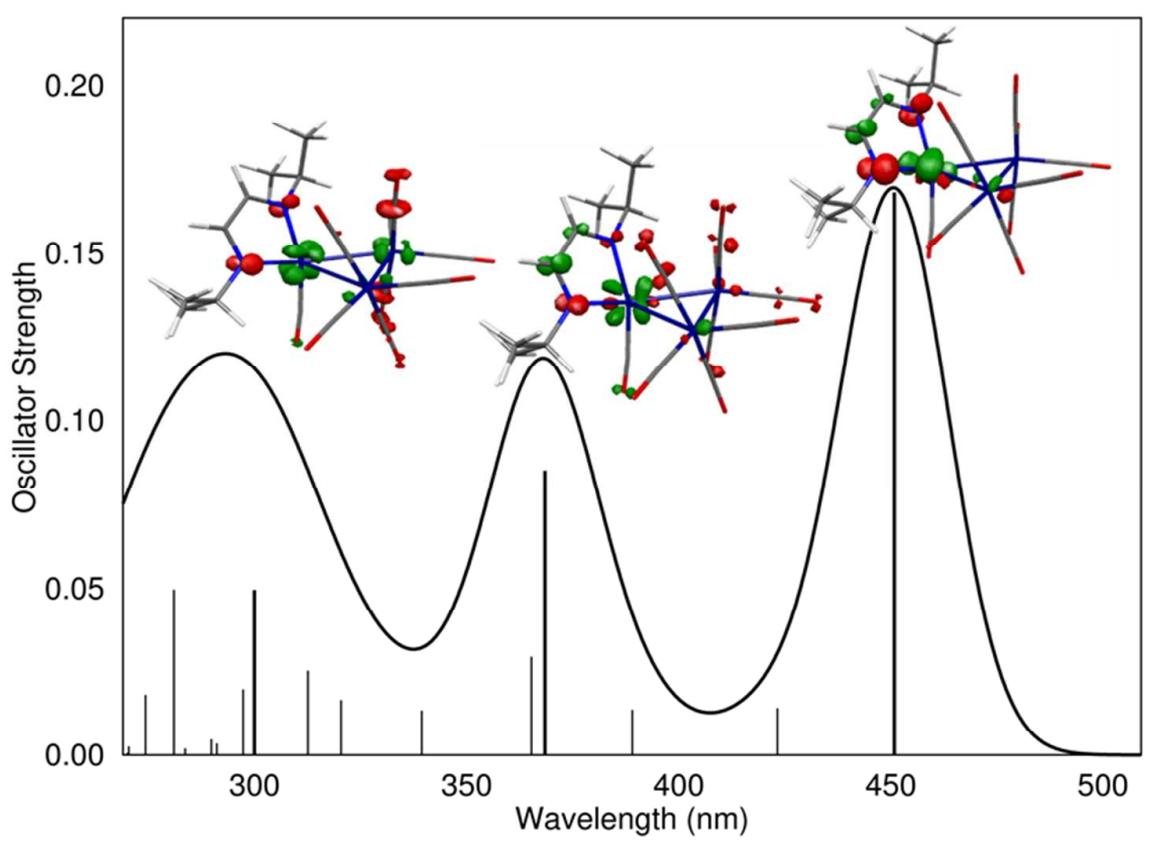

Figure 7. TD-DFT calculated excitations (vertical lines) and simulated electronic spectrum of $\left[\mathrm{Os}_{3}(\mathrm{CO})_{10}(\mathrm{DAB})\right]$. The EDDM plots for the relevant excitations (highlighted vertical lines) are also shown, green and red corresponding to a decrease and increase in electron density, respectively.

The decrease in the SBLCT character of the low-energy transition is apparent in the EDDM plots in Figures 5, 6, and 7, when going from BPY to IMP to DAB, respectively. It reflects the difference in the solvatochromic behavior of the low energy transition observed for the BPY and IMP clusters (Table 3), but not for the DAB one. These different features, arising from the characteristics of the frontier orbitals, are also responsible for the surprising energy order of the lowest energy transition, which does not follow the "expected" extension of the $\alpha$-diimine $\pi$ system, but results from a delicate balance of several factors.

The higher-energy absorption bands also depend on the $\alpha$-diimine. In the cluster $\left[\mathrm{Os}_{3}(\mathrm{CO})_{10}(\mathrm{BPY})\right]$, both $\mathrm{L}, \mathrm{L}+1$, and $\mathrm{L}+2$ are BPY $\pi^{*}$ orbitals (Figure 4), while the three highest occupied MOs correspond to the Os-Os $\sigma$-bonds. Therefore, the second and third transitions (entries 2,3 in Table 3) have the same nature as the first one (SBLCT) and can be assigned to the band experimentally observed at $2.47 \mathrm{eV}$, which displays solvatochromism. In the next calculated absorptions (entries $4,5,7$ ), the excitation to $\mathrm{L}+3$ is most important. The orbital $\mathrm{L}+3$ is both Os-Os $\sigma^{*}$ and $\mathrm{Os}-\mathrm{C}(\mathrm{O}) \pi^{*}$, with a residual contribution from the $\alpha$-diimine. Therefore, it is very similar in nature to the occupied orbitals (from $\mathrm{H}$ to $\mathrm{H}-4$ ), and the transitions from $\mathrm{H}, \mathrm{H}-1, \mathrm{H}-2, \mathrm{H}-3$ and H-4 to L +3 can no longer be considered SBLCT. They should not exhibit solvatochromism and 
can be assigned to the band observed at $3.06 \mathrm{eV}$. The EDDM plots depicted in Figures 5 are in line with this character.

The calculated excitations 1,2 , and 3 of $\left[\mathrm{Os}_{3}(\mathrm{CO})_{10}(\mathrm{IMP})\right]$ involve the same orbitals, namely, starting in $\mathrm{H}, \mathrm{H}-1, \mathrm{H}-2$ or H-3 and ending always in the LUMO. Their essentially SBLCT nature should be very similar; they probably correspond to the bands experimentally observed at 2.06, 2.2, and $2.55 \mathrm{eV}$, all of them having significant solvatochromism. The excitation 4 (Table 3) is $68 \% \mathrm{H}-1$ to $\mathrm{L}+2$. As can be seen in Figure 4, antibonding $\mathrm{L}+2$ is delocalized over the carbonyl groups $\left(\mathrm{Os}-\mathrm{C}(\mathrm{O}) \pi^{*}\right)$ and the three osmium atoms $\left(\sigma^{*}\right)$, like core-bonding $\mathrm{H}-1$, so that the excitation 4 has lost the SBLCT character of the lower-lying electronic transitions. The EDDM plots depicted in Figure 6 are consistent with these assignments.

In $\left[\mathrm{Os}_{3}(\mathrm{CO})_{10}(\mathrm{DAB})\right]$, the higher-energy transitions involve the HOMO and other occupied orbitals (H-2, H-3, H-4, H-5, H-6, with a strong contribution from the metal (Os-Os bonding) and carbonyls (Os- $\mathrm{C}(\mathrm{O})$ bonding) in some of them. The excitation ends in the LUMO, but, as the energy rises, with a higher weigh of $\mathrm{L}+1, \mathrm{~L}+2$, and $\mathrm{L}+3$ (no significant contribution from the $\alpha$ diimine) and an increasing localization on the carbonyls along with a decreasing localization on DAB. The role of the carbonyls is well visible in Figure 7, the colors indicating, as a global effect, a charge transfer from Os to the carbonyls.

\section{Resonance Raman Excitation Profiles}

The resonance Raman $(\mathrm{rR})$ spectra of the clusters $\left[\mathrm{Os}_{3}(\mathrm{CO})_{10}(\alpha\right.$-diimine $\left.)\right](\alpha$-diimine $=$ BPY, IMP and $\mathrm{DAB}$ ) were measured at various excitation wavelengths of the $\mathrm{Ar}^{+}$- and dye lasers between 457.9 and $610 \mathrm{~nm}^{27}$ The $\mathrm{rR}$ spectra were recorded in $\mathrm{KNO}_{3}$ pellets to avoid the photochemical isomerization of the $\alpha$-diimine ligand in $\left[\mathrm{Os}_{3}(\mathrm{CO})_{10}(\mathrm{IMP})\right]$ and $\left[\mathrm{Os}_{3}(\mathrm{CO})_{10}(\mathrm{DAB})\right]$ taking place in the solution. ${ }^{3}$ The corresponding $\mathrm{rR}$ excitation profiles are presented, giving the intensitydependence of the rR bands on the excitation wavelength. With their aid, the assignment of the different absorptions in the visible region of the absorption spectra is facilitated. The rR spectra of the clusters with $\alpha$-diimine $=$ BPY and IMP show enhanced Raman bands in the $1400-1600 \mathrm{~cm}^{-1}$ region belonging to mixed skeletal $v(\mathrm{CC})$ and $v(\mathrm{CN})$ vibrational modes of the $\alpha$-diimine ligand. The frequencies and band patterns compare well with those reported for related mononuclear $\alpha$ diimine complexes, e.g., $\left[\mathrm{Ru}(\mathrm{BPY})_{3}\right]^{2+}\left(\right.$ ref. $\left.^{28}\right),\left[\mathrm{Cr}(\mathrm{CO})_{4}(\mathrm{BPY})\right]\left(\right.$ ref. $\left.^{29}\right),\left[\mathrm{W}(\mathrm{CO})_{4}(\mathrm{IMP})\right]\left(\right.$ ref. $\left.^{30}\right)$ and $\left[\mathrm{Ru}(\mathrm{I})(\mathrm{Me})(\mathrm{CO})_{2}(\mathrm{IMP})\right]\left(\right.$ ref. $\left.^{25}\right)$. In addition, the resonantly enhanced Raman band around $2080 \mathrm{~cm}^{-1}$ is attributed to the highest-frequency $v(\mathrm{CO})$ stretching mode. The rR excitation profiles for the two most intense $v(\mathrm{CC}) / v(\mathrm{CN})$ modes and for the $v(\mathrm{CO})$ mode are given in Figure 8 . The 
profiles show that all three vibrational modes are resonantly enhanced on excitation into the lowest-energy absorption band. The excitation profiles for $\left[\mathrm{Os}_{3}(\mathrm{CO})_{10}(\mathrm{IMP})\right]$ (Figure $8 \mathrm{~b}$ ) reproduce the first shoulder of the lowest-energy absorption band, but not the second one. Those for $\left[\mathrm{Os}_{3}(\mathrm{CO})_{10}(\mathrm{BPY})\right]$ (Figure $\left.8 \mathrm{a}\right)$ decrease more steeply at the high energy side of the first absorption band. In the $\mathrm{rR}$ spectrum of $\left[\mathrm{Os}_{3}(\mathrm{CO})_{10}(\mathrm{DAB})\right]$ the $v_{\mathrm{s}}(\mathrm{CN})$ vibrational band at $1478 \mathrm{~cm}^{-}$ ${ }^{1}$ has only a low intensity, while the DAB deformation modes ${ }^{31}$ at 958 and $843 \mathrm{~cm}^{-1}$ and the $\delta(\mathrm{Os}-$ $\mathrm{CO})$ mode at $613 \mathrm{~cm}^{-1}$ are very strong. The $\mathrm{rR}$ excitation profiles for the $\delta(\mathrm{DAB})$ and $v_{\mathrm{s}}(\mathrm{CN})$ modes (Figure $8 \mathrm{c}$ ) reproduce the lowest-energy band of the absorption spectrum. It should be noted that this lowest-energy band is shifted to longer wavelengths in the solid state $\left(\lambda_{\max }=559\right.$ $\mathrm{nm}$ in $\mathrm{KBr} v s 521 \mathrm{~nm}$ in toluene).
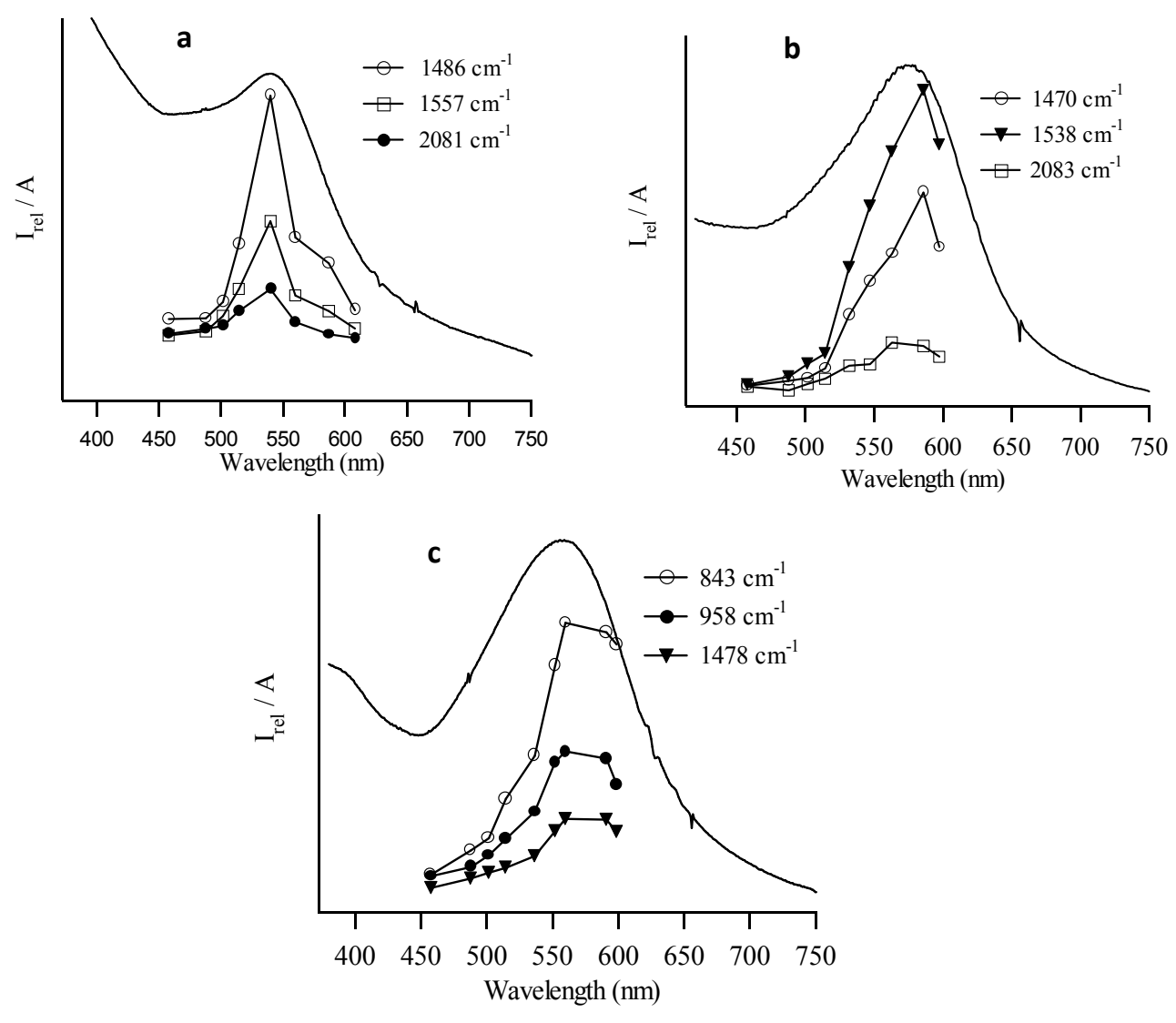

Figure 8. Resonance Raman excitation profiles for selected vibrational modes of $\left[\mathrm{Os}_{3}(\mathrm{CO})_{10}(\mathrm{BPY})\right](\mathrm{a}),\left[\mathrm{Os}_{3}(\mathrm{CO})_{10}(\mathrm{IMP})\right](\mathrm{b})$ and $\left[\mathrm{Os}_{3}(\mathrm{CO})_{10}(\mathrm{DAB})\right](\mathrm{c})$ in $\mathrm{KNO}_{3}$ pellets. The intensities $I_{\text {rel }}$ are given relative to the $1050 \mathrm{~cm}^{-1}$ peak of $\mathrm{KNO}_{3}$. The corresponding solid-state visible absorption spectra were recorded in $\mathrm{KBr}$ pellets. 
The LUMO of $\left[\mathrm{Os}_{3}(\mathrm{CO})_{10}(\alpha\right.$-diimine $\left.)\right]$, for $\alpha$-diimine $=$ BPY and IMP, has mainly the $\alpha$-diimine $\pi^{*}$ character; the same applies for $L+1$ and $L+2$ of the BPY cluster, and for $L+1$ of the IMP cluster. Consequently, the first group of electronic transitions introduces a significant charge transfer character (SBLCT) responsible for the solvatochromic behavior of the lowest-lying absorption band and the shoulders on its high-energy side. This charge transfer assignment agrees with the strongly resonantly enhanced Raman intensities of the $\alpha$-diimine (BPY, IMP) skeletal stretching modes. On the other hand, $\mathrm{L}+2$ of $\left[\mathrm{Os}_{3}(\mathrm{CO})_{10}(\mathrm{IMP})\right]$ is delocalized over the triosmium carbonyl core and the $\mathrm{H}-1 \rightarrow \mathrm{L}+2$ transition does not belong to the SBLCT group. Notably, no resonance Raman effect was observed for the $\alpha$-diimine-localized $v_{\mathrm{s}}(\mathrm{CC}) / v_{\mathrm{s}}(\mathrm{CN})$ stretching modes upon light excitation into the high-energy shoulder of the lowest absorption band of $\left[\mathrm{Os}_{3}(\mathrm{CO})_{10}(\mathrm{BPY})\right]$. At present, there is no straightforward explanation for this observation. ${ }^{32}$ The strong resonant enhancement of the DAB deformation modes and the $\delta(\mathrm{Os}-\mathrm{CO})$ mode in the Raman spectra of $\left[\mathrm{Os}_{3}(\mathrm{CO})_{10}(\mathrm{DAB})\right]$ corresponds with the strongly delocalized nature of the HOMO and LUMO in this case (Figure 4) and the negligible charge transfer nature of the $\mathrm{H} \rightarrow \mathrm{L}$ transition dominating the lowest-energy electronic excitation (Table 3, Figure 7).

\section{Photochemistry: Wavelength-Dependent Quantum Yields}

The clusters $\left[\mathrm{Os}_{3}(\mathrm{CO})_{10}(\alpha\right.$-diimine $\left.)\right]$ produce open-triangle zwitterions upon irradiation with visible light in pyridine as the strongly coordinating solvent. ${ }^{1,2}$ At room temperature, these zwitterions largely react thermally back within a few minutes, but at sufficiently low temperatures they remain stable and the photoreaction quantum yields $\Phi_{\lambda}$ of their formation can smoothly be determined, using a cryostatted cell (see Experimental Section). For $\alpha$-diimine = iPr-IMP (or IMP in this work) and $N$-isopropyl 2-iminoethylpyridine (iPr-IEP; Chart 1), the values of $\Phi_{\lambda}$ were reported previously only for $\mathrm{Ar}^{+}$-laser excitation wavelengths ranging between 457.9 and 514.5 $\mathrm{nm} .^{2}$ These excitation wavelengths merely cover the higher-energy shoulders and not the intense lowest-energy absorption band of the clusters.

The quantum yields $\Phi_{\lambda}$, presented in Table 4 and Figure 9, were measured in pyridine at 263 $\mathrm{K}$ and represent the photogeneration of pyridine-stabilized zwitterion by dye-laser irradiation into the low-lying absorption band of $\left[\mathrm{Os}_{3}(\mathrm{CO})_{10}(\mathrm{IMP})\right]: \lambda_{\text {irr }}=514.5,541.6,577.0$ and $596.0 \mathrm{~nm}$. Under the experimental conditions, the maximum of this band lies at $555 \mathrm{~nm}$. The excitation at $\lambda_{\text {irr }}$ $=577.0 \mathrm{~nm}$ and $597.0 \mathrm{~nm}$ falls exclusively into the lowest-energy electronic transition (No.1 in Table 3), while the $\lambda_{\text {irr }}=514.5 \mathrm{~nm}$ excitation mainly into the electronic transition No.2 (Table 3) seen as the poorly resolved shoulder at ca $512 \mathrm{~nm}$ (Figure 9). An intermediate situation applies for 
the $541.6 \mathrm{~nm}$ excitation. It is expected that for higher-energy excitation the quantum yields for the zwitterion formation are identical to $\Phi_{514.5}$. This expectation is based on the wavelengthindependent $\left(457.9 \leq \lambda_{\text {irr }} \leq 514.5\right)$ quantum yields for the IMP-based photoisomerization of this cluster in THF, and those for the zwitterion formation in case of closely related $\left[\mathrm{Os}_{3}(\mathrm{CO})_{10}(\mathrm{iPr}-\right.$ IEP)] (and other derivatives of these clusters). ${ }^{2,3,4}$ In addition to the wavelength-dependence, the quantum yields for the zwitterion formation from $\left[\mathrm{Os}_{3}(\mathrm{CO})_{10}(\alpha\right.$-diimine $\left.)\right](\alpha$-diimine $=$ IMP, RIEP; $\lambda_{\text {irr }} \leq 514.5 \mathrm{~nm}$ ) proved to be temperature-dependent, corresponding to activation energies ranging between 440 and $718 \mathrm{~cm}^{-1}$ (Table 4). These quantum yields are compared with the values previously determined for $\left[\mathrm{Os}_{3}(\mathrm{CO})_{10}(\mathrm{IMP})\right]$ and $\left[\mathrm{Os}_{3}(\mathrm{CO})_{10}(\mathrm{iPr}-\mathrm{IEP})\right] .^{2,3}$ The quantum yields $\Phi_{514.5}$ and $\Phi_{541}$ are $c a .0 .21$, exceeding significantly the $\Phi_{577}$ and $\Phi_{596}$ values of $c a .0 .13$. The quantum yield determined for the $514.5 \mathrm{~nm}$ excitation is about $20 \%$ higher than the value reported earlier. ${ }^{2}$ This difference reflects the different experimental set-up used for the two measurements (see Experimental Section).

Table 4. Quantum yields $\Phi_{\lambda}\left(\times 10^{2}\right)$ for the photochemical formation of pyridine-coordinated zwitterion and $\alpha$-diimine (IMP) photoisomerization of selected $\left[\mathrm{Os}_{3}(\mathrm{CO})_{10}(\alpha\right.$-diimine)] clusters.

\begin{tabular}{|c|c|c|c|c|c|c|c|}
\hline$\lambda_{\text {irr }}(\mathrm{nm})$ & 457.9 & 488.0 & 514.5 & 541.6 & 577.0 & 596.0 & reaction \\
\hline Os/IMP ${ }^{a, b}$ & & & $20.0(0.4)$ & $21.1(2.0)$ & $12.6(0.8)$ & $13.8(0.8)$ & $i$ \\
\hline $\mathrm{Os} / \mathrm{IMP}^{a, c}$ & & & $16.2^{e}$ & & & & $i$ \\
\hline Os/iPr-IEP ${ }^{a, c}$ & $29.2^{f}$ & 28.3 & $28.2^{g}$ & & & & $i$ \\
\hline Os/nPr-IEP ${ }^{a, c}$ & & & $18.3^{h}$ & & & & $i$ \\
\hline $\mathrm{Os} / \mathrm{IMP}^{c, d}$ & 0.295 & 0.319 & 0.299 & & & & $j$ \\
\hline
\end{tabular}

${ }^{a}$ Quantum yields determined in pyridine at $263 \mathrm{~K} .{ }^{b}$ This work. ${ }^{c}$ Values taken from ref. $2 .{ }^{d}$ Quantum yields determined in THF at $298 \mathrm{~K} .{ }^{e} E_{\mathrm{a}}(514.5 \mathrm{~nm})=718 \mathrm{~cm}^{-1} \cdot{ }^{f} E_{\mathrm{a}}(457.9 \mathrm{~nm})=511 \mathrm{~cm}^{-1} \cdot{ }^{g} E_{\mathrm{a}}(514.5 \mathrm{~nm})=$ $440 \mathrm{~cm}^{-1} \cdot{ }^{h} E_{\mathrm{a}}(514.5 \mathrm{~nm})=689 \mathrm{~cm}^{-1} \cdot{ }^{i}$ Zwitterion formation. ${ }^{j}$ IMP ligand isomerization (see Scheme 1). 


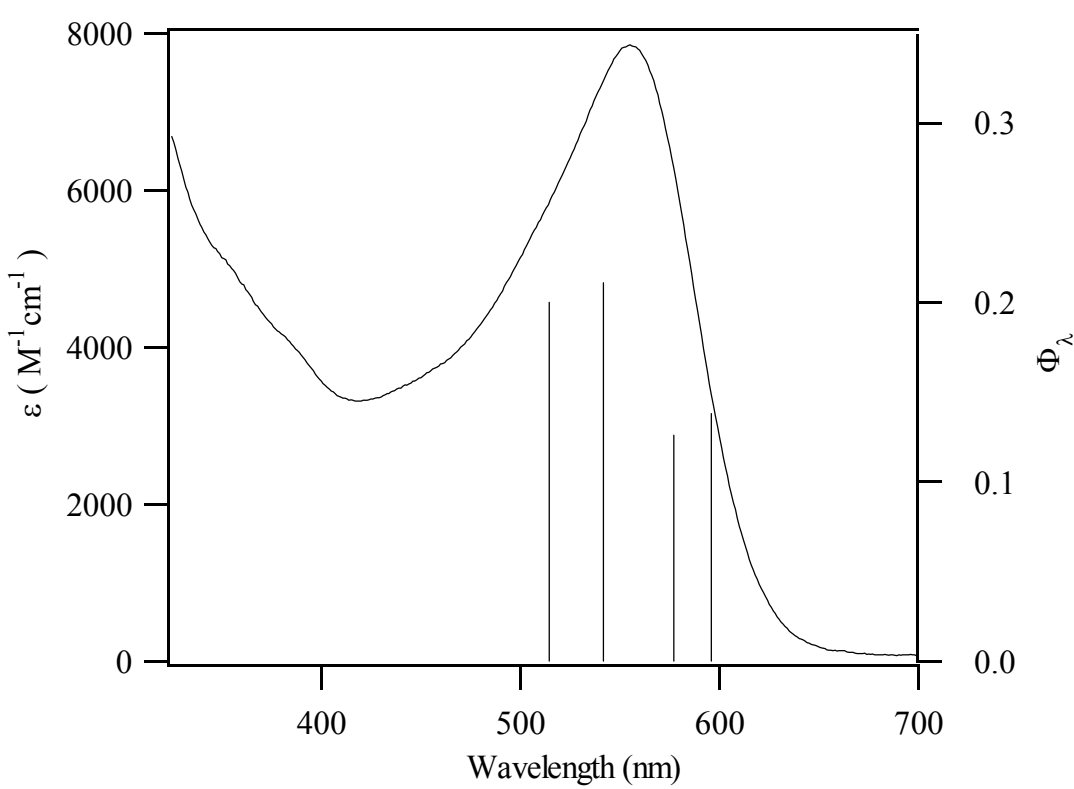

Figure 9. Plot of the UV-vis absorption spectrum of $\left[\mathrm{Os}_{3}(\mathrm{CO})_{10}(\mathrm{IMP})\right]$ and the wavelengthdependent quantum yields $\Phi_{\lambda}$ for the zwitterion formation in pyridine at $263 \mathrm{~K}$.

As highlighted in Introduction, the clusters $\left[\mathrm{Os}_{3}(\mathrm{CO})_{10}(\alpha\right.$-diimine $\left.)\right]$ undergo a variety of photochemical reactions depending on the $\alpha$-diimine ligand ( $\pi^{*}$ LUMO energy, aromaticity), solvent coordinating ability, and temperature. The common initial step is the cleavage of an Os-Os( $\alpha$-diimine) $\sigma$-bond (see Scheme 1), namely Os1-Os3 (Figure 1, Table 1), as confirmed by the DFT calculations in the preceding section. This reaction was argued to occur from a repulsive $\sigma \sigma^{*}$ state separated by a potential barrier from an optically populated $\sigma \pi^{*}$ (SBLCT) excited state, for $\alpha$-diimine $=\mathrm{R}$-BPY, R-IMP. ${ }^{8,10}$ The existence of the potential barrier may also explain the wavelength dependence of the photoreaction quantum yield (Figure 9). It needs to be noted, however, that the zwitterions can form via two independent routes, viz. $(A)$ a heterolytic Os-Os bond cleavage from an exciplex (solvated excited cluster), and $(B)$ a homolytic Os-Os bond cleavage to form a biradical intermediate undergoing an intramolecular charge-separation upon solvent coordination (see Scheme 1). ${ }^{8,10}$ The height of the potential barrier, determining the branching between the decay to the ground state and the dissociative state, will also vary on going from the non-relaxed to relaxed $\sigma \pi^{*}$ excited state on the ps time scale. The direct optical 
population of the repulsive state of $\left[\mathrm{Os}_{3}(\mathrm{CO})_{10}(\mathrm{IMP})\right]$ below $500 \mathrm{~nm}$ can be excluded on the grounds of the results in the preceding theoretical section.
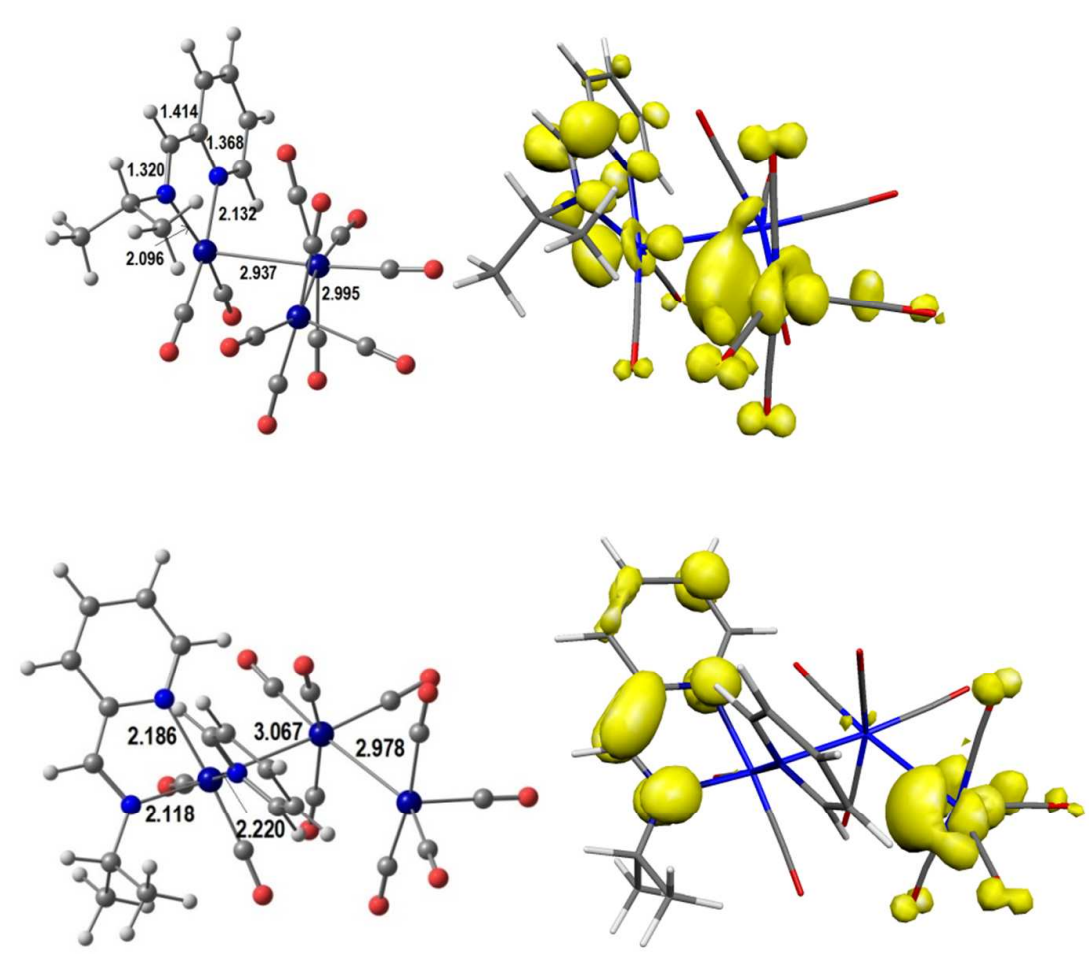

Figure 10. DFT-calculated structures of the photogenerated open-core biradicals (triplet state) derived from $\left[\mathrm{Os}_{3}(\mathrm{CO})_{10}(\mathrm{IMP})\right]$, with selected distances $(\AA)$ : top - reactive species with $(\alpha-$ diimine $\left.^{\bullet-}\right)$ Os $1^{+} \ldots$ Os $3^{\bullet}$; bottom - solvent-stabilized species with $\left(\alpha\right.$-diimine $\left.{ }^{\bullet-}\right)\left(\right.$ py)Os $1^{+} \ldots$ Os $3^{\bullet}$ $(p y=$ pyridine). The spin density distribution is shown on the left.

To enlighten the photochemical behavior using the theoretical approach, we have optimized several relevant intermediates. We started by obtaining the geometries and energies of the lowestenergy (gas-phase) singlet (S) and triplet (T) excited states (Scheme 1). As discussed above (Table 1 ), the major geometric change in both states is the lengthening of the ( $\alpha$-diimine)Os1-Os3 bond, suggesting that the electron excitation favors the Os-Os bond cleavage. Although this result may not be too evident from the observation of the HOMO, in the open shell excited states the $\alpha$ and $\beta$ molecular orbitals may change relative to the orbitals of the ground-state cluster, and therefore, the optimized excited states give a better description of the potential reactivity. The triplet excited state can be labelled as ${ }^{3} \sigma \pi^{*}$, corresponding to $\left(\alpha\right.$-diimine $\left.{ }^{\bullet-}\right)$ Os $1^{+}-$Os $3^{\bullet}$ according to the spin 
density plot. It relaxes to a lower-energy open triplet state, $\left(\alpha\right.$-diimine $\left.{ }^{\bullet-}\right)$ Os $1^{+} \ldots$ Os $3^{\bullet}$, with a very large Os1... Os3 distance of $4.524 \AA$ and an Os1-Os2-Os3 angle of $99.4^{\circ}$ (Figure 10, top). This is the theoretical representation of initial processes along the dominant homolytic (biradical) path $B$ in Scheme 1. We have also optimized the geometry of the biradical formed by the reaction with pyridine (py) in the ${ }^{3} \sigma \pi^{*}$ excited state (Figure 10, bottom). Although these two structures are very similar, the two remaining Os-Os bonds differ by almost $0.1 \AA$. The shorter one is spanned by Os2-Os3 in the triplet state. The Os1-Os2-Os3 angle is $103^{\circ}$, and the $\left(\alpha\right.$-diimine ${ }^{\bullet-}$ )(py)Os $1^{+} \ldots$ Os $3^{\bullet}$ distance reaches $4.717 \AA$. The diagram with the relative energies of all these species is shown in Scheme 2, which can now be compared with Scheme 1. The absorption at 492 $\mathrm{nm}$ leads to a vibrational excited singlet state, which relaxes to the lowest-energy vibrational state, and may further convert to a $16.6 \mathrm{kcal} \mathrm{mol}^{-1}$ more stable triplet by intersystem crossing. In both the singlet and triplet $\sigma \pi^{*}$ excited states, the Os1-Os3 bond (Figure 1) has been significantly weakened (the dashed line in Scheme 2). A new biradical intermediate with a much longer Os1...Os3 distance (no bond) and a lower potential energy is obtained. The reaction with the donor pyridine solvent may yield a lower-energy open-core triplet biradical containing pyridine at Os1. These species may convert back to the ground state. The spin density plots shown in Figure 10 help to confirm their biradical nature. The concomitant intramolecular electron transfer converting the pyridine-stabilized biradical to the corresponding long-lived diamagnetic zwitterion (see Scheme 1 and the above Photochemistry section) was not modelled in this DFT study. The alternate photoisomerization path for IMP (Scheme 1) was not observed in pyridine and therefore also not considered here. Both processes, originating in the open-core biradical state, require dynamic interaction between the photoreduced $\alpha$-diimine ligand and the Os 3 radical site. 


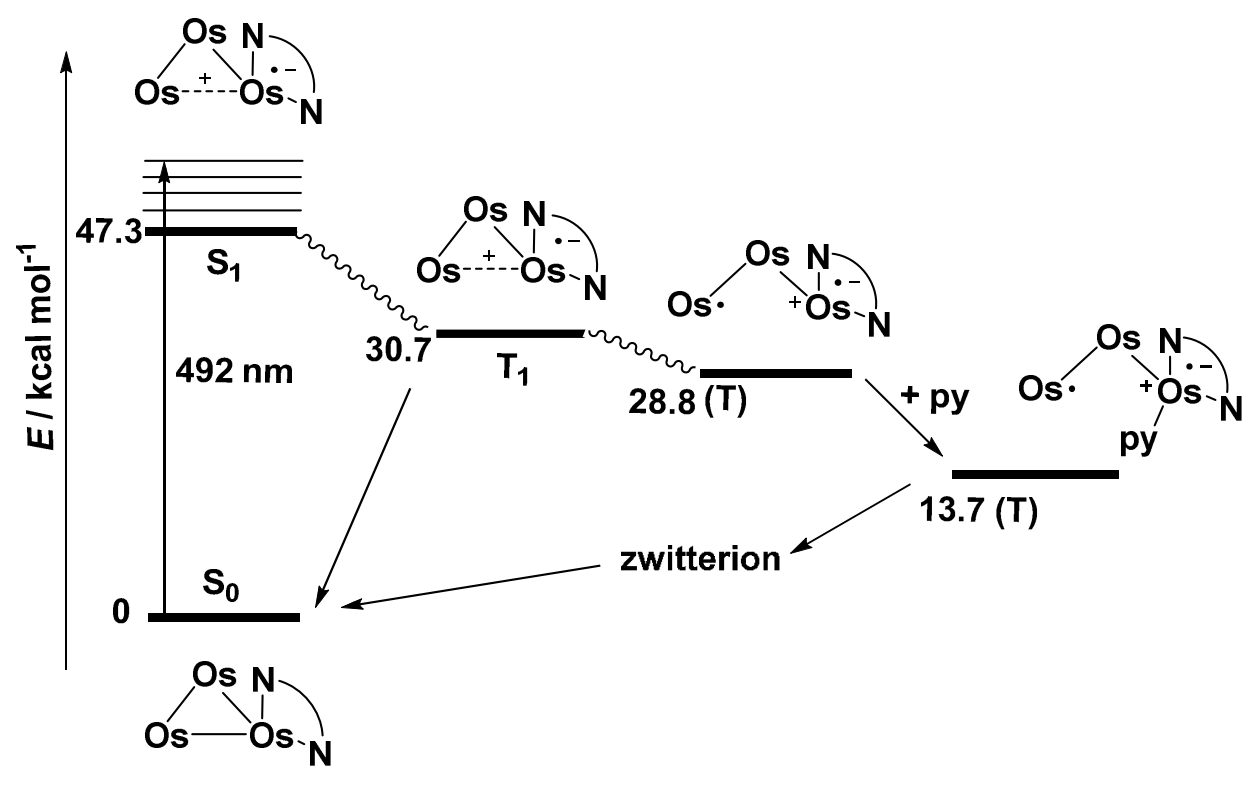

Scheme 2. Calculated biradical photoreactivity path (cf. Scheme 1, path $B$ ) of $\left[\mathrm{Os}_{3}(\mathrm{CO})_{10}(\mathrm{IMP})\right]$ in pyridine. Based on experimental evidence, the transformation of the cluster core in the relaxed ${ }^{3} \sigma \pi^{*}\left(\mathrm{~T}_{1}\right)$ excited stated to the triplet biradicals involves crossing a small potential barrier to a dissociative state.

\section{Conclusions}

This study presents the first accurate density functional theory description of the optically populated lowest excited states of the clusters $\left[\mathrm{Os}_{3}(\mathrm{CO})_{10}(\alpha\right.$-diimine $\left.)\right]$, for $\alpha$-diimine $=2,2^{\prime}-$ bipyridine (BPY), $N$-isopropyl 2-iminomethylpyridine (iPr-IMP, or IMP in this work), and $N, N^{\prime}-$ diisopropyl-1,4-diaza-1,3-butadiene (iPr-DAB, or DAB in this work), which has been achieved with the Coulomb-attenuating method CAM-B3LYP. The strongly $\sigma-\pi$ mixed character of the frontier orbitals in the case of $\alpha$-diimine $=\mathrm{DAB}$ explains the negligible charge-transfer character of the low-energy excited stated and corresponding near to zero change in the cluster dipole moment upon visible photoexcitation proven experimentally by the resonance Raman excitation profile and insensitivity of the visible electronic absorption to solvent dipole variation. It is now fully understood why $\left[\mathrm{Os}_{3}(\mathrm{CO})_{10}(\mathrm{DAB})\right]$ absorbs in the visible region photons of a higher energy than $\left[\mathrm{Os}_{3}(\mathrm{CO})_{10}(\mathrm{IMP})\right]$ and $\left[\mathrm{Os}_{3}(\mathrm{CO})_{10}(\mathrm{bpy})\right]$ despite the lowest energy of the DAB $\pi^{*} \mathrm{LUMO}$ compared to the IMP and bpy ligands with aromatic pyridyl rings. The strong SBLCT, $\sigma(\mathrm{Os}-\mathrm{Os})-$ to- $\pi^{*}(\alpha$-diimine $)$, character of the low-energy excited states for $\alpha$-diimine $=$ IMP was investigated in a greater detail by modelling the lengthening of one of the Os-Os(IMP) $\sigma$-bonds. The subsequent cleavage of this bond was shown to produce triplet biradicals as the dominant 
photochemical path from the ${ }^{3} \sigma \pi^{*}$ excited state revealed by time-resolved molecular spectroscopic studies in the past. The slower homolytic biradical pathway was appreciably well modeled with DFT in the presence of pyridine coordinating at the electron-deficient $\mathrm{Os}^{+}$-(IMP) site, which causes an ultimate intramolecular transformation into a long-lived zwitterion. The wavelength (and temperature ${ }^{2}$ ) dependence of the photoreaction quantum yields for the light-induced formation of the open-core zwitterion $(\mathrm{CO})_{4} \mathrm{Os}^{-}-\mathrm{Os}(\mathrm{CO})_{4}-\mathrm{Os}^{+}(\mathrm{py})(\mathrm{CO})_{2}(\mathrm{IMP})$ has provided an additional evidence for a small reaction barrier ${ }^{10,11}$ separating the optically populated ${ }^{1} \sigma \pi^{*}$ and relaxed ${ }^{3} \sigma \pi^{*}$ excited states $\left(S_{1}\right.$ and $T_{1}$ in Scheme 2$)$ from a repulsive state.

\section{Experimental Section}

\section{Computational Details}

All DFT calculations were performed with Gaussian09. ${ }^{33}$ The triple- $\zeta$ basis set augmented with an $f$ polarization function, LANL2TZ(f), was used for osmium along with the associated effective core potential (ECP), ${ }^{34}$ both downloaded from the EMSL Basis Set Library. ${ }^{35}$ For the remaining elements, the standard $6-311++\mathrm{G}^{* *}$ basis set, comprising both polarization and diffuse functions, was employed. Geometry optimizations were performed without symmetry constraints in the gas phase and in toluene (IEFPCM calculation with radii and non-electrostatic terms from the SMD solvation $\operatorname{model}^{36}$ ).

Given that in the previous study ${ }^{17}$ it was impossible to reproduce the experimental order of the lowest energy band absorption of the three $\left[\mathrm{Os}_{3}(\mathrm{CO})_{10}(\alpha\right.$-diimine $\left.)\right]$ clusters, a series of DFT functionals were tested in TD-DFT calculations, namely, the hybrids PBE1PBE (also known as PBE0), ${ }^{37}$ and the popular B3LYP, ${ }^{38}$ the pure PW91PW91 functional, ${ }^{39}$ the hybrid exchange-correlation functional using the Coulomb-attenuating method CAM-B3LYP, ${ }^{40}$ and the Minnesota functional M06-2X. ${ }^{41}$ From the tested functionals, CAM-B3LYP was the only capable of reproducing the experimental trend in the gas phase and was therefore used throughout this work. The calculated lowest-energy transitions for all tested functionals are given in SI (Table S2). Notice that the M06-2X functional (gas phase calculations) gave the second-best results, however, the predicted order (IMP $<$ BPY $=$ DAB) no longer reproduces the experimental trend $(\mathrm{IMP}<$ $\mathrm{BPY}<\mathrm{DAB}$ ). Introduction of solvent effects (toluene) on TD-DFT calculations using the previously solvent optimized structures leads to even poorer results (Table S2) as the previous correct trend obtained for CAM-B3LYP is lost, whereas the M06-2X results also become worse. 
The lowest-singlet excited state was optimized using a TDDFT optimization as implemented in Gaussian09, whereas the optimization of the triplet state was performed by defining the correspondent multiplicity on the calculation.

The scripts to plot the electron density difference maps (EDDMs) were retrieved from the GaussSum package. ${ }^{42}$ The experimentally determined oscillator strengths $\left(f_{\text {exp }}\right)$ for the visible absorption band were calculated using the equation $f_{\exp }=4.319 \times 10^{-9} \varepsilon_{\max } \Delta v$. Structures were drawn using Chemcraft ${ }^{43}$ and the orbitals with Molekel. ${ }^{44}$

\section{Materials and Preparations}

The clusters $\left[\mathrm{Os}_{3}(\mathrm{CO})_{10}(\alpha\right.$-diimine $\left.)\right]$ ( $\alpha$-diimine $=2,2^{\prime}$-bipyridine (BPY), $N$-isopropyl 2iminomethylpyridine (IMP), and $N, N^{\prime}$-diisopropyl-1,4-diaza-1,3-butadiene (DAB)) were synthesized according to published procedures. ${ }^{1,2}$ Their purity was checked by IR and ${ }^{1} \mathrm{H}$ NMR spectroscopies. The solvents used for UV-vis spectroscopy were of spectroscopic grade (Merck: $\mathrm{CCl}_{4}$, toluene, $\mathrm{CHCl}_{3}, \mathrm{CH}_{2} \mathrm{Cl}_{2}$, acetone, acetonitrile, DMSO, THF), and were used as purchased. Pyridine and toluene (Aldrich) used for the photochemical experiments were freshly distilled before use under an atmosphere of dry nitrogen from $\mathrm{CaH}_{2}$ and a sodium wire, respectively. All photochemical samples were prepared under careful exclusion of light and using standard inertgas techniques.

\section{Spectroscopic Measurements}

Electronic absorption spectra were recorded on Varian Cary 4E and Hewlett-Packard 8453 diode spectrophotometers. Resonance Raman spectra of the studied triosmium clusters dispersed in $\mathrm{KNO}_{3}$ pellets were recorded on a Dilor XY spectrometer equipped with a Wright Instruments CCD detector. A Spectra Physics 2040E $\mathrm{Ar}^{+}$-laser was used as the excitation source and as a pump for Coherent Radiation Model 590 and 490 dye lasers with Rhodamine 6G or Coumarin 6 dye solutions. Intensities of the resonantly enhanced Raman bands were measured relative to the 1050 $\mathrm{cm}^{-1}$ Raman band of $\mathrm{KNO}_{3}$.

\section{Photoreaction Quantum Yield Measurements}

Quantum yields for the light-induced disappearance of $\left[\mathrm{Os}_{3}(\mathrm{CO})_{10}(\mathrm{IMP})\right]$ in pyridine were determined by measuring the decay of the absorption band of the cluster at $555 \mathrm{~nm}$ with a Varian Cary $4 \mathrm{E}$ spectrophotometer. Corrections were made for the absorbance of the photoproduct. The quartz sample cuvette was cooled using an Oxford Instruments DN 1704/54 liquid nitrogen cryostat equipped with quartz optical windows. The sample was irradiated inside the sample 
compartment of the spectrophotometer by the laser lines of a Spectra Physics Model 2040E $\mathrm{Ar}^{+}-$ laser, or by those of the dye lasers (vide supra). The photon flux was determined in front of and behind the sample cuvette with two Applied Photophysics quantum counter detectors, thereby allowing direct determination of the number of photons absorbed. Corrections were made for reflection of light at the cuvette windows. The quantum counters were calibrated before and after each single quantum yield measurement with standard solutions of fulgide dyes Aberchrome $540 \mathrm{P}^{45}$ or Aberchrome $999 \mathrm{P}^{46}$ in dry degassed toluene, prepared on a vacuum line. For each excitation wavelength, the quantum yield was determined at least in duplicate; each measurement typically involved ten irradiation intervals during which the solution was stirred.

\section{Suppporting Information}

The Supporting Information is available free of charge on the ACS Publications website at DOI: Energies of the frontier orbitals (in eV) of the three $\left[\mathrm{Os}_{3}(\mathrm{CO})_{10}(\alpha\right.$-diimine $\left.)\right]$ clusters $(\alpha$-diimine $=$ DAB, IMP, BPY) - Table S1. Calculated lowest-energy electronic transitions for all tested functionals - Table S2. Molecular structures of the three $\left[\mathrm{Os}_{3}(\mathrm{CO})_{10}(\mathrm{IMP})\right]$ isomers and their relative energies in $\mathrm{kcal} \mathrm{mol}^{-1}$ - Figure S1. Coordinates of all the calculated species, available as an XYZ file.

\section{Author Information}

\section{Corresponding authors}

* E-mail: $\underline{\text { f.hartl@,reading.ac.uk }}$

*E-mail: mjc@fc.ul.pt or mjc@ciencias.ulisboa.pt

\section{ORCID}

František Hartl: 0000-0002-7013-5360

Vanessa Farelo Santos: 0000-0001-8564-0952

Paulo Costa: 0000-0002-0492-6666

Maria José Calhorda: 0000-0002-6872-3569

\section{Acknowledgements}

We thank the Fundação para a Ciência e a Tecnologia, Portugal, for financial support (UID/MULTI/00612/2013). P.J.C. acknowledges FCT, Fundo Social Europeu, and Programa 
Operacional Potencial Humano for the Investigador FCT contract (IF/00069/2014), project (IF/00069/2014/CP1216/CT0006), and M.J.C. grant SFRH/BSAB/135473/2017. This work was also co-financed by Programa Operacional Regional de Lisboa (Lisboa 2020), Portugal 2020, FEDER/FN, and European Union under project number 28455 (LISBOA-01-0145-FEDER028455). The experimental work, carried out by M.J.B. at the University of Amsterdam, was financially supported by the NWO Council for Chemical Science, NWO-CW (F.H., Project No. 348-032). The work on this manuscript (F.H.) was co-funded by the spin-out project Spectroelectrochemistry at the University of Reading. 


\section{For Table of Contents Only}

\section{ToC Gaphics}

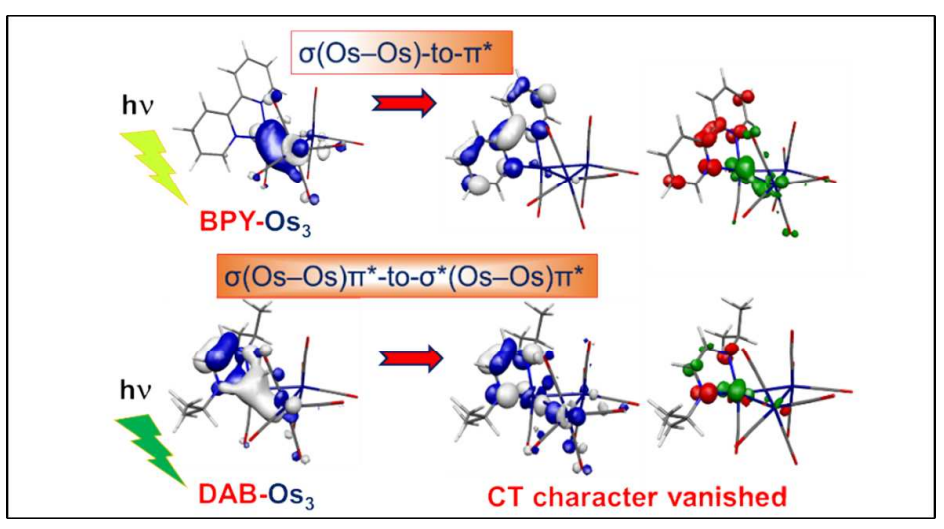

\section{ToC Synopsis}

The CAM-B3LYP DFT method was employed successfully to reproduce the experimental lowenergy electronic absorption and describe accurately the corresponding optically populated excited states of three selected triangular clusters $\left[\mathrm{Os}_{3}(\mathrm{CO})_{10}(\alpha\right.$-diimine $\left.)\right]$ : for (a) the least $\pi$-delocalized system with 2,2'-bipyridine (BPY), (b) the strongly $\pi$-delocalized system with $N, N^{\prime}$-diisopropyl1,4-diaza-1,3-butadiene (DAB), and (c) the intermediate case with $N$-isopropyl 2iminomethylpyridine (IMP). For the IMP cluster, the biradical photoreactivity path towards opencore zwitterions has also been calculated. 


\title{
References
}

\begin{abstract}
${ }^{1}$ Van Outersterp, J. W. M.; Garriga Oostenbrink, M. T.; Nieuwenhuis, H. A.; Stufkens, D. J.; Hartl, F. Photochemistry of the Clusters $\mathrm{Os}_{3}(\mathrm{CO})_{10}(\mathrm{~L})\left(\mathrm{L}=2,2^{\prime}\right.$-Bipyridine, 2,2'-Bipyrimidine, 2,3-Dipyrid-2-ylpyrazine, 2,3-Dipyrid-2-ylbenzoquinoxaline). Reversible Opening of an Os-Os Bond with Formation of a Zwitterion. Inorg. Chem. 1995, 34, 6312-6318.
\end{abstract}

${ }^{2}$ Nijhoff, J.; Bakker, M. J.; Hartl, F.; Stufkens, D. J.; Fu, W.-F.; Van Eldik, R. Photochemistry of the Triangular Clusters $\mathrm{Os}_{3}(\mathrm{CO})_{10}(\alpha$-diimine): Homolysis of an Os-Os Bond and SolventDependent Formation of Biradicals and Zwitterions. Inorg. Chem. 1998, 37, 661-668.

${ }^{3}$ Nijhoff, J.; Bakker, M. J.; Hartl, F.; Stufkens, D. J. Mechanistic study of the photoisomerization of $\mathrm{Os}_{3}(\mathrm{CO})_{10}(\mathrm{~L})$ in which $\mathrm{L}(\mathrm{L}=1,4-\mathrm{di}-\mathrm{R}-1,4$-diazabutadiene (R-DAB) or pyridine-2carbaldehyde N-R-imine (R-PyCa)) changes its coordination from $\sigma, \sigma-\mathrm{N}, \mathrm{N}^{\prime}$ into $\sigma-\mathrm{N}, \mu_{2}-\mathrm{N}^{\prime}, \eta^{2}-$ $\mathrm{C}=\mathrm{N}^{\prime}$. J. Organomet. Chem. 1999, 572, 271-281.

${ }^{4}$ Nijhoff, J.; Hartl, F.; Stufkens, D. J. Light-Induced Insertion of a CO Ligand into an Os-N Bond of the Clusters $\mathrm{Os}_{3}(\mathrm{CO})_{10}(\mathrm{~L})$, Where L Represents a Potentially Terdentate $N, N^{\prime}$-Chelating $\alpha$ Diimine. Organometallics 1999, 18, 4380-4389.

${ }^{5}$ Nijhoff, J.; Hartl, F.; Stufkens, D. J. Light-Induced Insertion of a CO Ligand into an Os-N Bond of the Clusters $\mathrm{Os}_{3}(\mathrm{CO})_{10}(\mathrm{~L})$, Where L Represents a Potentially Terdentate $N, N^{\star}$ '-Chelating $\alpha$ Diimine. Organometallics 1999, 18, 4380-4389.

${ }^{6}$ Bakker, M. J.; Hartl, F.; Stufkens, D. J.; Jina, O. S.; Sun, X.-Z.; George, M. W. AlkeneStabilized Biradical and Zwitterionic Photoproducts of the Clusters $\left[\mathrm{Os}_{3}(\mathrm{CO})_{10}(\alpha\right.$-diimine $\left.)\right]$ : A Time-Resolved Transient Absorption and Infrared Study. Organometallics, 2000, 19, 4310-4319. ${ }^{7}$ Vergeer, F. W.; Calhorda, M. J.; Matousek, P.; Towrie, M; Hartl, F. Marked influence of the bridging carbonyl ligands on the photo- and electrochemistry of the clusters $\left[\mathrm{Ru}_{3}(\mathrm{CO})_{8}(\mu-\mathrm{CO})_{2}(\alpha-\right.$ diimine $)$ ( $\alpha$-diimine $=2,2^{\prime}$-bipyridine, 4,4'-dimethyl-2,2'-bipyridine and 2,2'-bipyrimidine). Dalton Trans. 2003, 4084-4099.

${ }^{8}$ Vergeer, F. W.; Kleverlaan, C. J.; Matousek, P.; Towrie, M.; Stufkens, D. J.; Hartl F. Redox Control of Light-Induced Charge Separation in a Transition Metal Cluster: Photochemistry of a Methyl Viologen-Substituted $\left[\mathrm{Os}_{3}(\mathrm{CO})_{10}(\alpha\right.$-diimine) $]$ Cluster. Inorg. Chem. 2005, 44, 1319-1331. ${ }^{9}$ Vergeer, F. W.; Lutz, M.; Spek, A. L.; Calhorda, M. J.; Stufkens, D.J.; Hartl, F. Heterosite Effects in Novel Heteronuclear Clusters $\left[\mathrm{Os}_{2} \mathrm{Ru}(\mathrm{CO})_{11}\left(\mathrm{PPh}_{3}\right)\right]$ and $\left[\mathrm{Os}_{2} \mathrm{Ru}(\mathrm{CO})_{10}(2 \square\right.$ acetylpyridine $\square N \square$ isopropylimine)]. Eur. J. Inorg. Chem. 2005, 2206-2222.

${ }^{10}$ Vergeer, F.W.; Bakker, M.J.; Kleverlaan, C.J.; Hartl, F.; Stufkens, D. J. Light-induced formation of zwitterions and biradicals from the cluster $\left[\mathrm{Os}_{3}(\mathrm{CO})_{10}\left({ }^{i} \mathrm{Pr}-\mathrm{AcPy}\right)\right]$ studied with picosecond UV-vis and nanosecond IR spectroscopies. Coord. Chem. Rev. 2002, 229, 107-112.

${ }^{11}$ Stufkens, D. J.; Van der Graaf, T.; Stor, G. J.; Oskam, A. The photochemistry of $(\mathrm{CO})_{5} \mathrm{MnMn}(\mathrm{CO})_{3}(\alpha$-diimine $)$ and $\mathrm{XMn}\left(\mathrm{CO}_{3}\right)(\alpha$-diimine $)(\mathrm{X}=$ halide $)$ complexes. Coord. Chem. Rev. 1991, 111, 331-336.

${ }^{12}$ Stufkens, D. J.; Van Outersterp, J. W. M.; Oskam, A.; Rossenaar, B. D.; Stor, G. J. The photochemical formation of organometallic radicals from $\alpha$-diimine complexes having a metalmetal, metal-alkyl or metal-halide bond. Coord. Chem. Rev. 1994, 132, 147-154.

${ }^{13}$ Rossenaar, B. D.; Lindsay, E.; Stufkens, D. J.; Vlček Jr., A. Properties and dynamics of the $\sigma\left(\mathrm{M}^{\prime}-\mathrm{Re}\right) \pi *$ excited state of photoreactive dinuclear $\mathrm{LnM}^{\prime}-\mathrm{Re}(\mathrm{CO})_{3}(\alpha$-diimine $)\left(\mathrm{LnM}^{\prime}=\mathrm{Ph}_{3} \mathrm{Sn}\right.$, $(\mathrm{CO})_{5} \mathrm{Mn},(\mathrm{CO})_{5} \mathrm{Re} ; \alpha$-diimine $=$ bpy', iPr-PyCa, iPr-DAB) complexes studied by time-resolved emission and absorption spectroscopies. Inorg. Chim. Acta 1996, 250, 5-14.

${ }^{14}$ Stufkens, D. J.; Aarnts, M. P.; Nijhoff, J.; Rossenaar, B. D.; Vlček Jr., A. Excited states of metal-metal bonded diimine complexes vary from extremely long lived to very reactive with formation of radicals or zwitterions. Coord. Chem. Rev. 1998, 171, 93-97. 
${ }^{15}$ Parr, R. G.; Yang, W. Density Functional Theory of Atoms and Molecules; Oxford University Press, New York, 1989

${ }^{16}$ Bauernschmitt, R.; Ahlrichs, R. Treatment of electronic excitations within the adiabatic approximation of time dependent density functional theory. Chem. Phys. Lett.1996, 256, 454-464. ${ }^{17}$ M. J. Calhorda, M. J.; Hunstock, E.; Veiros, L. F.; Hartl, F., Eur. J. Inorg. Chem. Theoretical studies of [Os3(CO)10( $\alpha$-diimine)]: structures, frontier orbitals and bonding. 2001, 223-231. ${ }^{18}$ Zoet, R.; Jastrzebski, J. T. B. H.; van Koten, G.; Mahabiersing, T.; Vrieze K.; Heijdenrijk, D.; Stam C. H., Organometallics. Synthesis and characterization of two isomers of decacarbonyl(1,4dialkyl-1,4-diaza-1,3-butadiene)triosmium: $\mathrm{Os}_{3}(\mathrm{CO})_{10}(\mathrm{R}-\mathrm{DAB})$. Fluxional behavior of $\mathrm{Os}_{3}(\mathrm{CO})_{10}(i-\mathrm{Pr}-\mathrm{DAB}(4 \mathrm{e}))$. Molecular structures of the $48 \mathrm{e} \mathrm{Os}_{3}(\mathrm{CO})_{10}(i-\mathrm{Pr}-\mathrm{DAB}(4 \mathrm{e})$ and of the 50 e cluster $\mathrm{Os}_{3}(\mathrm{CO})_{10}(\mathrm{c}-\mathrm{Pr}-\mathrm{DAB}(6 \mathrm{e}))$ containing a $4 \mathrm{e}$ donor $\sigma, \sigma^{\prime}-\mathrm{N}, \mathrm{N}^{\prime}$ ' and a $6 \mathrm{e} \sigma-\mathrm{N}, \mu_{2}-\mathrm{N}^{\prime}, \eta^{2}-$ $\mathrm{C}=\mathrm{N}^{\prime}$ bonded R-DAB ligand, respectively. 1988, 7, 2108-2117.

${ }^{19}$ Leadbeater, N. E.; Lewis, J.; Raithby, P. R.; Ward, G. N., J. Chem. Soc., Dalton Trans. Photochemistry of $\left[\mathrm{Ru}_{3}(\mathrm{CO})_{12}\right]$ with nitrogen heterocycles. 1997, 2511-2516.

${ }^{20}$ Groom, C. R.; Bruno, I. J.; Lightfoot M. P., Ward, S. C. The Cambridge Structural Database. Acta Cryst. 2016, B72, 171-179.

${ }^{21}$ Manuta, D. M.; Lees, A. J. Solvent and substituent effects on the lowest energy excited states of $\mathrm{M}(\mathrm{CO})_{4}($ diimine $)(\mathrm{M}=\mathrm{Cr}$, Mo, W) complexes. Inorg. Chem. 1983, 22, 3825-3828.

${ }^{22}$ Stufkens, D. J. Spectroscopy, photophysics and photochemistry of zerovalent transition metal $\alpha-$ diimine complexes. Coord. Chem. Rev. 1990, 104, 39-112.

${ }^{23}$ Stufkens, D. J. The Remarkable Properties of $\alpha$-Diimine Rhenium Tricarbonyl Complexes in Their Metal-to-Ligand Charge-Transfer (MLCT) Excited States. Comments Inorg. Chem. 1992, $13,359-385$.

${ }^{24}$ Lees, A. J. Organometallic complexes as luminescence probes in monitoring thermal and photochemical polymerizations. Coord. Chem. Rev. 1998, 177, 3-35.

${ }^{25}$ Nieuwenhuis, H. A.; Stufkens, D. J.; Oskam, A. Remarkable Influence of X and R on the Charge Transfer Character (MLCT or XLCT) of the Complexes $\left[\mathrm{Ru}(\mathrm{X})(\mathrm{R})(\mathrm{CO})_{2}(\mathrm{~L})\right](\mathrm{X}=$ Halide, Triflate; $\mathrm{R}=$ Alkyl; $\mathrm{L}=\alpha$-Diimine): an UV-Vis Absorption and Resonance Raman Study. Inorg. Chem. 1994, 33, 3212-3217.

${ }^{26}$ Rossenaar, B. D.; Stufkens, D. J.; Vlček Jr., A. Halide-Dependent Change of the LowestExcited-State Character from MLCT to XLCT for the Complexes $\operatorname{Re}(\mathrm{X})(\mathrm{CO})_{3}$ ( $\alpha$-diimine $)(\mathrm{X}=\mathrm{Cl}$, Br, I; $\alpha$-diimine = bpy, iPr-PyCa, iPr-DAB) Studied by Resonance Raman, Time-Resolved Absorption, and Emission Spectroscopy. Inorg. Chem. 1996, 35, 2902-2909.

${ }^{27}$ The observed $\mathrm{rR}$ frequencies in $\mathrm{KNO}_{3}$ are: 494, 513, 1023, 1175, 1276, 1325, 1485, 1556, 1606, 2024 and $2080 \mathrm{~cm}^{-1}$ for $\left[\mathrm{Os}_{3}(\mathrm{CO})_{10}(\mathrm{BPY})\right] ; 345,481,520,553,594,615,972,1019,1132,1162$, $1239,1253,1303,1470,1539,1581,1613,2083 \mathrm{~cm}^{-1}$ for $\left[\mathrm{Os}_{3}(\mathrm{CO})_{10}(\mathrm{IMP})\right] ; 294,417,473,502$, $547,613,843,930,958,1157,1478,1907,1956,2000,2090 \mathrm{~cm}^{-1}$ for $\left[\mathrm{Os}_{3}(\mathrm{CO})_{10}(\mathrm{DAB})\right.$.

${ }^{28}$ Mallick, P. K.; Danzer, G. D.; Strommen, D. P.; Kincaid, J. R. Vibrational spectra and normalcoordinate analysis of tris(bipyridine)ruthenium(II). J. Phys. Chem. 1988, 92, 5628-5634.

${ }^{29}$ Vlček Jr., A.; Grevels, F.-W.; Snoeck, T. L.; Stufkens, D. J. Ground and electronically excited states of $\mathrm{Cr}(\mathrm{CO})_{4}$ (bipyridine): energy factored force field analysis of $\mathrm{CO}$ stretching vibrations and resonance Raman study. Inorg. Chim. Acta 1998, 278, 83-90.

${ }^{30}$ Balk, R. W.; Snoeck, T. L.; Stufkens, D. J.; Oskam, A. (Diimine)carbonyl complexes of chromium, molybdenum, and tungsten: relationship between resonance Raman spectra and photosubstitution quantum yields upon excitation within the lowest metal to diimine chargetransfer band. Inorg. Chem. 1980, 19, 3015-3021.

${ }^{31}$ Aarnts, M. P.; Wilms, M. P.; Stufkens, D. J.; Baerends, E. J.; Vlček Jr., A. $\sigma-\pi^{*}$ Electronic Transition of the Di- and Trinuclear Complexes $\mathrm{Ru}(\mathrm{E})\left(\mathrm{E}^{\prime}\right)(\mathrm{CO})_{2}(\mathrm{iPr}-\mathrm{DAB})$ : Resonance Raman, Electronic Absorption, Emission, and Density Functional Study $\left(\mathrm{E}=\mathrm{Me}, \mathrm{SnPh}_{3}, \mathrm{M}(\mathrm{CO})_{5} ; \mathrm{E}^{\prime}=\right.$ 
$\mathrm{M}(\mathrm{CO})_{5} ; \mathrm{M}=\mathrm{Mn}, \mathrm{Re} ;$ iPr-DAB $=N, N^{\prime}$-Diisopropyl-1,4-diaza-1,3-butadiene). Organometallics 1997, 16, 2055-2062.

${ }^{32}$ Both self-absorption and resonance de-enhancement are unlikely. The latter effect may occur when contributions of more than one electronic transition to the Raman scattering destructively interfere. However, in such a case only a dip in the rR profiles is observed instead of the entire disappearance of the resonance enhancement.

${ }^{33}$ Gaussian 09, Frisch, M. J.; Trucks, G. W.; Schlegel, H. B.; Scuseria, G. E.; Robb, M. A.; Cheeseman, J. R.; Scalmani, G.; Barone, V.; Mennucci, B.; Petersson, G. A.; Nakatsuji, H.; Caricato, M.; Li, X.; Hratchian, H. P.; Izmaylov, A. F.; Bloino, J.; Zheng, G.; Sonnenberg, J. L.; Hada, M.; Ehara, M.; Toyota, K.; Fukuda, R.; Hasegawa, J.; Ishida, M.; Nakajima, T.; Honda, Y.; Kitao, O.; Nakai, H.; Vreven, T.; Montgomery, J. A., Jr.; Peralta, J. E.; Ogliaro, F.; Bearpark, M.; Heyd, J. J.; Brothers, E.; Kudin, K. N.; Staroverov, V. N.; Kobayashi, R.; Normand, J.; Raghavachari, K.; Rendell, A.; Burant, J. C.; Iyengar, S. S.; Tomasi, J.; Cossi, M.; Rega, N.; Millam, J. M.; Klene, M.; Knox, J. E.; Cross, J. B.; Bakken, V.; Adamo, C.; Jaramillo, J.; Gomperts, R.; Stratmann, R. E.; Yazyev, O.; Austin, A. J.; Cammi, R.; Pomelli, C.; Ochterski, J. W.; Martin, R. L.; Morokuma, K.; Zakrzewski, V. G.; Voth, G. A.; Salvador, P.; Dannenberg, J. J.; Dapprich, S.; Daniels, A. D.; Farkas, Ö.; Foresman, J. B.; Ortiz, J. V.; Cioslowski, J.; Fox, D. J. Gaussian, Inc., Wallingford CT, 2009.

${ }^{34}$ Roy, L. E.; Hay, P. J.; Martin, R. L. Revised basis sets for the LANL effective core potentials. $J$. Chem. Theory Comput. 2008, 4, 1029-1031.

${ }^{35}$ Feller, D. The role of databases in support of computational chemistry calculations. J. Comp. Chem. 1996, 17, 1571-1586. (b) Schuchardt, K. L.; Didier, B. T.; Elsethagen, T.; Sun, L.; Gurumoorthi, V.; Chase, J.; Li, J.; Windus, T. L. Basis Set Exchange: a community database for computational sciences. J. Chem. Inf. Model. 2007, 47, 1045-1052.

${ }^{36}$ Marenich, A.V.; Cramer, C. J.; Truhlar, D.G. Universal Solvation Model Based on Solute Electron Density and on a Continuum Model of the Solvent Defined by the Bulk Dielectric Constant and Atomic Surface Tensions. J. Phys. Chem. B 2009, 113, 6378-6396.

${ }^{37}$ Adamo, C.; Barone, V. Toward reliable density functional methods without adjustable parameters: The PBE0 model. J. Chem. Phys. 1999, 110, 6158-6169.

${ }^{38}$ (a) Becke, A. D. Density-functional thermochemistry. III. The role of exact exchange. J. Chem. Phys. 1993, 98, 5648-5652. (b) Lee, C.; Yang, W.; Parr, R. G. Development of the Colle-Salvetti correlation-energy formula into a functional of the electron density. Phys. Rev. B 1988, 37, 785. ${ }^{39}$ (a) Perdew, J. P.; Chevary, J. A.; Vosko, S. H.; Jackson, K. A.; Pederson, M. R.; Singh, D. J.; Fiolhais, C. Atoms, molecules, solids, and surfaces: Applications of the generalized gradient approximation for exchange and correlation. Phys. Rev. B 1992, 46, 6671-6687. (b) Perdew, J. P.; Chevary, J. A.; Vosko, S. H.; Jackson, K. A.; Pederson, M. R.; Singh, D. J.; Fiolhais, C. Erratum: Atoms, molecules, solids, and surfaces: Applications of the generalized gradient approximation for exchange and correlation. Phys. Rev. B 1993, 48, 4978-4978.

${ }^{40}$ Yanai, T.; Tew, D. P.; Handy, N. C. A new hybrid exchange-correlation functional using the Coulomb-attenuating method (CAM-B3LYP). Chem. Phys. Lett. 2004, 393, 51-57.

${ }^{41}$ Zhao, Y.; Truhlar, D.G. The M06 suite of density functionals for main group thermochemistry, thermochemical kinetics, noncovalent interactions, excited states, and transition elements: two new functionals and systematic testing of four M06-class functionals and 12 other functionals. Theor. Chem. Acc., 2008, 120, 215-241.

${ }^{42}$ O’Boyle, N. M.; Tenderholt, A. L.; Langner, K. M. cclib: A library for package-independent computational chemistry algorithms. J. Comput. Chem. 2008, 29, 839-845.

${ }^{43}$ Chemcraft - graphical software for visualization of quantum chemistry computations. http://www.chemcraftprog.com/index.html 
${ }^{44}$ Portmann, S.; Lüthi, H. P. MOLEKEL: An Interactive Molecular Graphics Tool. Chimia 2000, $54,766-770$.

${ }^{45}$ Heller, H. G.; Langan, J. R. Photochromic heterocyclic fulgides. Part 3. The use of (E)- $\alpha-(2,5-$ dimethyl-3-furylethylidene)(isopropylidene)succinic anhydride as a simple convenient chemical actinometer. J. Chem. Soc., Perkin Trans. 1981, 2, 341-343.

${ }^{46}$ Kuhn, H. J.; Braslavsky, S. E.; Schmidt, R. Chemical actinometry (IUPAC Technical Report). Pure Appl. Chem. 2004, 76, 2105-2146. 

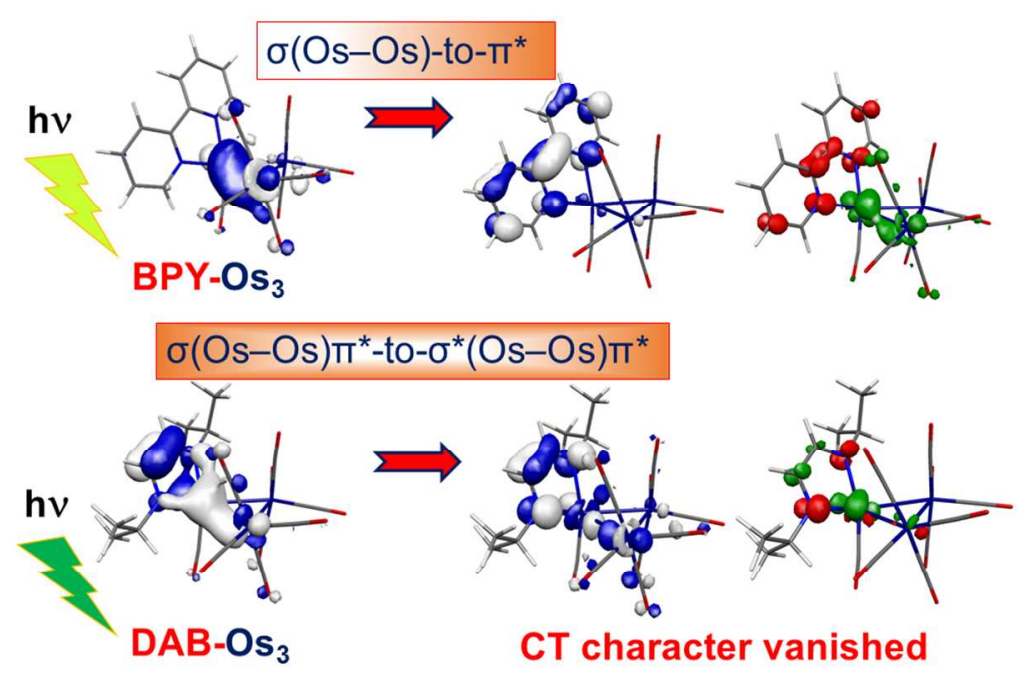

Graphics for ToC only

$338 \times 190 \mathrm{~mm}(96 \times 96$ DPI) 